\title{
A Parametrical Study on Convective Heat Transfer between High-Temperature Gas and Regenerative Cooling Panel
}

\author{
Jiangyu Hu, Ning Wang *, Jin Zhou and Yu Pan \\ College of Aerospace Science, National University of Defense Technology, Changsha 410073, China; \\ hujiangyu14@nudt.edu.cn (J.H.); zhoujin@nudt.edu.cn (J.Z.); panyu04@nudt.edu.cn (Y.P.) \\ * Correspondence: wangning07@nudt.edu.cn
}

check for updates

Citation: Hu, J.; Wang, N.; Zhou, J.;

Pan, Y. A Parametrical Study on Convective Heat Transfer between High-Temperature Gas and Regenerative Cooling Panel. Energies 2021, 14, 1784. https://doi.org/ $10.3390 /$ en14061784

Academic Editor: Phillip Ligrani

Received: 9 February 2021

Accepted: 18 March 2021

Published: 23 March 2021

Publisher's Note: MDPI stays neutral with regard to jurisdictional claims in published maps and institutional affiliations.

Copyright: (c) 2021 by the authors. Licensee MDPI, Basel, Switzerland. This article is an open access article distributed under the terms and conditions of the Creative Commons Attribution (CC BY) license (https:// creativecommons.org/licenses/by/ $4.0 /)$.

\begin{abstract}
Thermal protection is still one of the key challenges for successful scramjet operations. In this study, the three-dimensional coupled heat transfer between high-temperature gas and regenerative cooling panel with kerosene of supercritical pressure flowing in the cooling channels was numerically investigated to reveal the fundamental characteristics of regenerative cooling as well as its influencing factors. The SST $k$ - $\omega$ turbulence model with low-Reynolds-number correction provided by the pressure-based solver of Fluent 19.2 is adopted for simulation. It was found that the heat flux of the gas heated surface is in the order of $10^{6} \mathrm{~W} / \mathrm{m}^{2}$, and it declines along the flow direction of gas due to the development of boundary layer. Compared with cocurrent flow, the temperature peak of the gas heated surface in counter flow is much higher. The temperature and heat flux of the gas heated surface both rises with the static pressure and total temperature of gas. The heat flux of the gas heated surface increases with the mass flow rate of kerosene, and it hardly changes with the pressure of kerosene. Results herein could help to understand the real heat transfer process of regenerative cooling and guide the design of thermal protection systems.
\end{abstract}

Keywords: thermal protection; regenerative cooling panel; supercritical pressure; coupled heat transfer

\section{Introduction}

Thermal protection is one of the key challenges in the application of scramjet engines [1]. Among the available cooling methods, the active regenerative cooling using endothermic hydrocarbon fuel as coolant is recommended as the most effective way for its high efficiency and low performance loss [2-6].

Since temperature and heat flux are the crucial design parameters for thermal protection, many researchers conducted research to investigate the wall temperature and heat flux of scramjet engines. Kennedy et al. [7,8] experimentally measured the heat flux of the scramjet combustor walls by heat flux sensors, and it was found that the heat flux of the combustor wall varied from $200 \mathrm{~kW} / \mathrm{m}^{2}$ to $1500 \mathrm{~kW} / \mathrm{m}^{2}$. In order to measure the extremely high temperature and heat flux of the scramjet combustor, Li et al. [9] developed an integrated water-cooled sensor and conducted numerical and experimental investigations to test the response characteristics and stability of the sensor, calibration results indicated that the sensor could meet the measurement requirements. By installing heat-flux sensors on the combustor wall, systematic experimental research was carried out to obtain the wall heat flux distribution at different locations of the supersonic combustor, it was found that the equivalence ratio has little impact on the distribution of heat flux [10].

Compared with experimental measurements, numerical simulations could significantly reduce cost and save time. Numerical studies indicated that for a regenerative cooling combustor, the boundary conditions and heat transfer of the combustor wall could be solved by the gradient-based method [11]. The numerical investigation of Wang et al. [12] indicated that the wall heat flux is greatly influenced by the flow and combustion characteristics, which leads to the high non-uniform distribution of heat flux in the supersonic combustor. Besides, researchers found that the heat conduction of the combustor wall 
can be estimated by the conjugate gradient method, in which the transient temperature and heat flux of the inner wall is obtained through the measurement of outer wall temperature, and the difference between simulation results and experimental measurements was found to be less than $5 \%$ [13].

In the present research of aero engines, endothermic hydrocarbon fuel is recommended as the fuel because of its high volumetric energy density [14]. Since the operating pressure in the cooling channels is usually higher than the critical pressure, lots of work has been done to study the flow and heat transfer characteristics of hydrocarbon fuels at supercritical pressures [15,16]. According to Wang et al. [17], the heat transfer deterioration can be caused by the pseudo-film boiling in the near wall region. For kerosene flowing in a heated horizontal tube at supercritical pressures, the variation of density would induce buoyancy, which would lead to secondary flow and influence the heat transfer, and the buoyancy effect decreases with the rise of pressure because of smaller variation of density [18] In order to further understand the buoyancy effect, Sun et al. [19] conducted large eddy simulations and investigated the detailed flow and heat transfer of n-decane in a heated upward circular tube at supercritical pressures, and it was found that the influence of buoyancy is strongly related to the flowing state of fuel.

Thermal cracking would occur when the temperature of endothermic hydrocarbon fuel is pretty high, which would influence the flow and heat transfer [20]. According to Lei et al. [21], the cooling capacity can be promoted by thermal cracking, which is beneficial for the thermal protection. Therefore, the flow and heat transfer of endothermic hydrocarbon fuels with thermal pyrolysis was extensively studied. Based on their experimental studies, Li et al. [22] proposed a simplified molecular reaction kinetic model of high accuracy that can be used to simulate the pyrolysis of supercritical endothermic hydrocarbon fuels in heated tubes. Li et al. [23] also found that pyrolysis would enhance the heat transfer when heat flux is relatively low while the influence of pyrolysis on heat transfer at higher heat flux is much more complicated. The work of Xu et al. [24] indicated that the ribbed surface would greatly improve the heat transfer in the channel, leading to lower wall temperature and weakens the pyrolysis of the endothermic fuel.

Although there are many literatures concerning the thermal protection and regenerative cooling of scramjet engines, most of them has been simplified to a certain extent. For example, the electric heating experiments were used to model the thermal environment of the cooling channels $[25,26]$, or the flow and heat transfer characteristics of hydrocarbon fuel were numerically investigated at a given wall heat flux $[27,28]$. The coupled heat transfer of high-temperature gas and regenerative cooling panel are seldom taken into consideration in the existing literatures. It can be deduced that for convective heat transfer between high-temperature gas and combustor wall, higher wall temperature would lead to lower heat flux. However, for heat transfer of coolant in the cooling panel, higher wall temperature would lead to higher heat flux. The temperature and heat flux of the combustor wall may not match through separated research. Since the heat transfer of regenerative cooling is a strongly coupled process, it is better to solve the problem as a whole. Therefore, the three-dimensional coupled heat transfer between high-temperature gas, regenerative cooling panel with parallel cooling channels and kerosene of supercritical pressure are numerically investigated in this paper. The fundamental characteristics of coupled heat transfer as well as its influencing factors are studied and discussed combined with theoretical analysis. The simulation results herein could help to reveal the real heat transfer process of regenerative cooling and can be used for the design and optimization of thermal protection systems.

The block diagram of this paper is shown in Figure 1. 


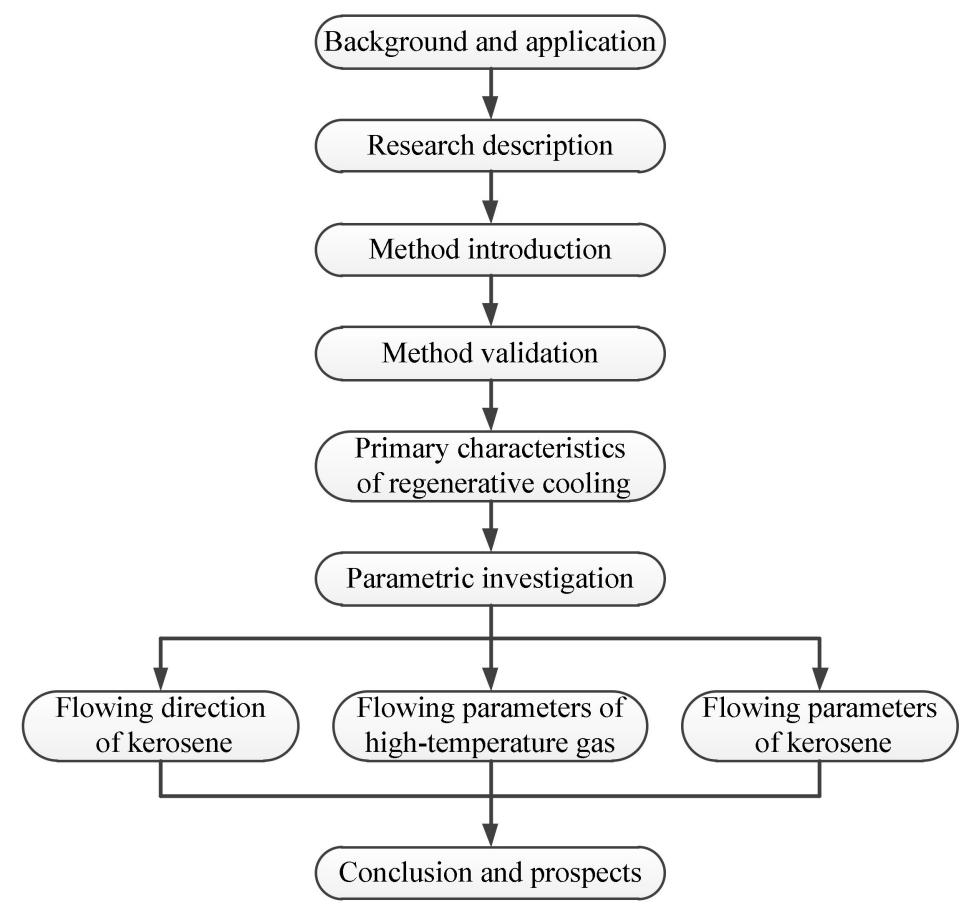

Figure 1. Block diagram of this paper.

\section{Numerical Methods}

\subsection{Governing Equations}

The finite volume method provided by the pressure-based solver of ANSYS Fluent 19.2 is used for numerical simulations in this study. The Reynolds averaging method is adopted to simulate the flow and heat transfer. For steady flow and heat transfer of fluid with no external force and heat source, the governing equations in Reynold's averaging are as follows.

Continuity equation:

$$
\frac{\partial}{\partial x_{i}}\left(\rho u_{i}\right)=0
$$

Momentum equation:

$$
\frac{\partial}{\partial x_{j}}\left(\rho u_{i} u_{j}\right)=-\frac{\partial P}{\partial x_{i}}+\frac{\partial}{\partial x_{j}}\left[\mu\left(\frac{\partial u_{i}}{\partial x_{j}}+\frac{\partial u_{j}}{\partial x_{i}}\right)-\frac{2}{3} \mu \delta_{i j} \frac{\partial u_{k}}{\partial x_{k}}\right]+\frac{\partial}{\partial x_{j}}\left(-\rho \overline{u_{i}^{\prime} u_{j}^{\prime}}\right)
$$

The Reynolds stress based on the Boussinesq hypothesis has the following form:

$$
-\rho \overline{u_{i}^{\prime} u_{j}^{\prime}}=\mu_{t}\left(\frac{\partial u_{i}}{\partial x_{j}}+\frac{\partial u_{j}}{\partial x_{i}}\right)-\frac{2}{3} \delta_{i j}\left(\rho k+\frac{\partial u_{k}}{\partial x_{k}}\right)
$$

Energy equation:

$$
\frac{\partial u_{i} \rho E}{\partial x_{i}}+\frac{\partial u_{i} P}{\partial x_{i}}=\frac{\partial}{\partial x_{j}}\left(\lambda \frac{\partial T}{\partial x_{j}}+\frac{c_{p} \mu_{t}}{\operatorname{Pr}_{t}} \frac{\partial T}{\partial x_{j}}\right)+\frac{\partial u_{i}}{\partial x_{j}}\left[\mu\left(\frac{\partial u_{i}}{\partial x_{j}}+\frac{\partial u_{j}}{\partial x_{i}}\right)-\frac{2}{3} \mu \delta_{i j} \frac{\partial u_{k}}{\partial x_{k}}\right]
$$

Tao et al. [29] numerically investigated the heat transfer of hydrocarbon fuel at supercritical pressures, and it was found that the SST $k-\omega$ model [30] is more accurate than other models in most cases. The work of Wang et al. [12] indicated that the SST $k-\omega$ model could accurately simulate the flow and reaction in the scramjet combustor and predict the heat flux of the combustor walls. Therefore, the SST $k-\omega$ turbulence model with low-Reynolds-number correction is adopted for simulation in this paper. 
Equation of turbulent kinetic energy $k$ :

$$
\frac{\partial}{\partial t}(\rho k)+\frac{\partial}{\partial x_{i}}\left(\rho k u_{i}\right)=\frac{\partial}{\partial x_{j}}\left(\Gamma_{k} \frac{\partial k}{\partial x_{j}}\right)+\widetilde{G}_{k}-Y_{k}+S_{k}
$$

Equation of specific dissipation rate $\omega$ :

$$
\frac{\partial}{\partial t}(\rho \omega)+\frac{\partial}{\partial x_{i}}\left(\rho \omega u_{i}\right)=\frac{\partial}{\partial x_{j}}\left(\Gamma_{\omega} \frac{\partial \omega}{\partial x_{j}}\right)+G_{\omega}-Y_{\omega}+D_{\omega}+S_{\omega}
$$

Detailed descriptions of the constants and the coefficients can be found in the work of Menter [30].

The three-dimensional heat conduction equation in the solid zone:

$$
\frac{\partial}{\partial x_{i}}\left(\lambda \frac{\partial T}{\partial x_{i}}\right)+\frac{\partial}{\partial x_{j}}\left(\lambda \frac{\partial T}{\partial x_{j}}\right)+\frac{\partial}{\partial x_{k}}\left(\lambda \frac{\partial T}{\partial x_{k}}\right)+\dot{q}=\rho c \frac{\partial T}{\partial \tau}
$$

For constant thermal conductivity without heat source, the steady-state heat conduction equation in the solid zone can be written as:

$$
\frac{\partial^{2} T}{\partial x_{i}^{2}}+\frac{\partial^{2} T}{\partial x_{j}^{2}}+\frac{\partial^{2} T}{\partial x_{k}^{2}}=0
$$

By combining the continuity equation, momentum equation and energy equation of the fluid while solving the heat conduction equation in the solid region, and adopting coupled heat transfer for the convective heat transfer between solid walls and fluid zone, the three-dimensional coupled heat transfer between high-temperature gas and regenerative cooling panel can be solved.

\subsection{Physical Model}

The detailed schematic diagram of a scramjet engine can be found in the work of Goyne et al [31]. The simplified schematic diagram of scramjet engine and regenerative cooling is shown in Figure 2. It can be seen that for regenerative cooling in scramjet engines, heat is transmitted from high-temperature gas to the cooling panel through convection, and is transferred inside the cooling panel through conduction, and finally it is absorbed by kerosene of supercritical pressure through convection. The heat transfer through radiation is not considered in this study because of its small proportion in total heat flux [32].

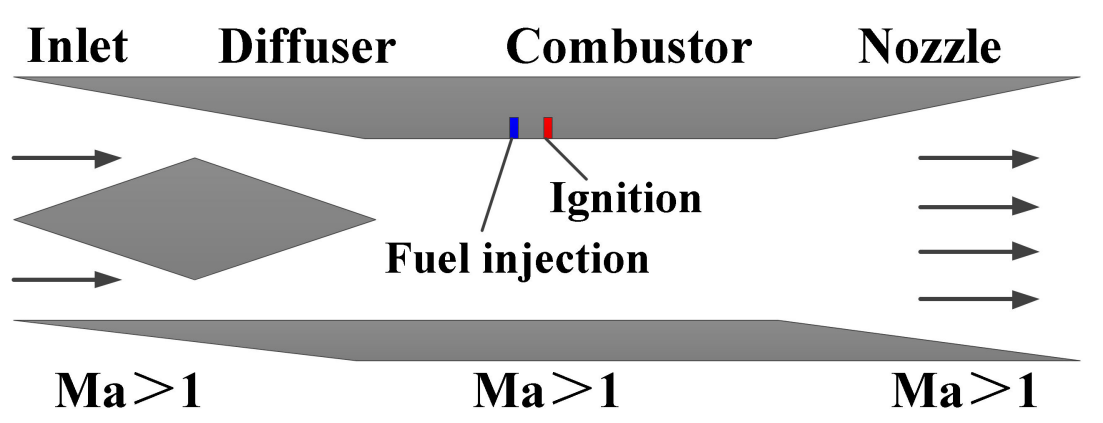

(a)

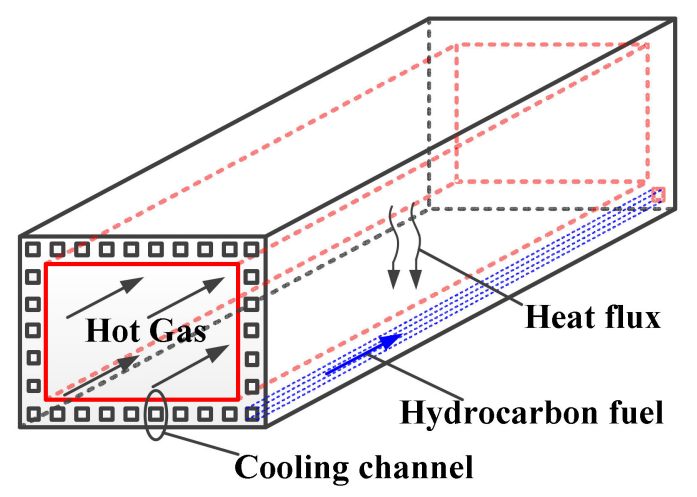

(b)

Figure 2. Schematic diagram of scramjet engine and regenerative cooling: (a) Scramjet engine (b) Regenerative cooling.

The experimental photos of scramjet engine and regenerative cooling are shown in Figure 3. The temperature and heat flux of the gas heated surface are measured by embedded thermocouples and heat flux sensors in the experiments. However, the installation of 
thermocouples and heat flux sensors would change the origin configuration of the cooling panel. Besides, the local flow and heat transfer characteristics are also affected by the installation of thermocouples and heat flux sensors, which may lead to significant errors. Therefore, the proposed research could help to reveal the heat transfer characteristics of regenerative cooling and its influencing factors.

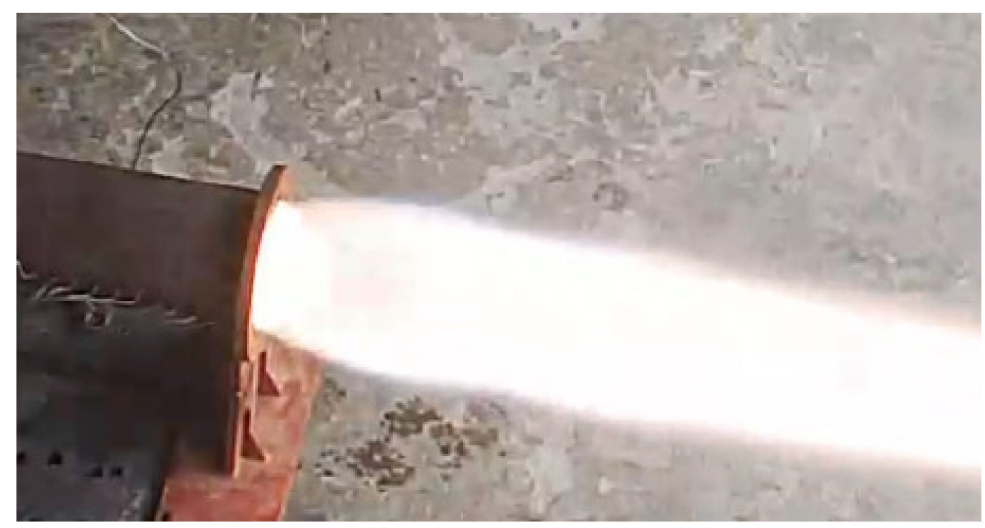

(a)

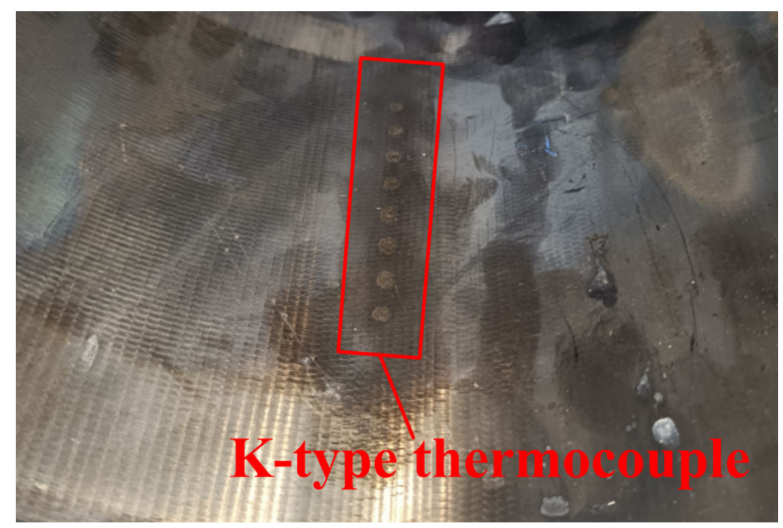

(b)

Figure 3. Experimental photos of scramjet engine and regenerative cooling: (a) high-temperature gas at the exhaust of a model scramjet combustor $(\mathbf{b})$ regenerative cooling panel.

The convective heat flux $q_{g}$ of the gas heated surface is calculated as:

$$
q_{g}=h_{g}\left(T_{a w}-T_{w g}\right)
$$

where $h_{g}$ is the convective heat transfer coefficient of high-temperature gas, $T_{a w}$ is the actual adiabatic wall temperature while $T_{w g}$ is the wall temperature of the gas heated surface.

The equivalent conductive heat flux $q_{p}$ in the cooling panel can be calculated as:

$$
q_{p}=\frac{\lambda}{\delta_{p}}\left(T_{w g}-T_{w c}\right)=h_{p, e q}\left(T_{w g}-T_{w c}\right)
$$

where $\lambda$ is the thermal conductivity of the panel material, $\delta_{p}$ is the thickness of the gas side wall, $h_{p, e q}$ can be considered as the equivalent heat transfer coefficient of the cooling panel and $T_{w c}$ is the wall temperature at the coolant side.

The equivalent convective heat flux $q_{c}$ in the cooling channels can be calculated as:

$$
q_{c}=h_{c, e q}\left(T_{w c}-T_{b}\right)
$$

where $h_{c, e q}$ is the equivalent convective heat transfer coefficient of kerosene and $T_{b}$ is the bulk temperature of kerosene. According to the energy conservation, we can get the following equation:

$$
q=h_{g}\left(T_{a w}-T_{w g}\right)=h_{p, e q}\left(T_{w g}-T_{w c}\right)=h_{c, e q}\left(T_{w c}-T_{b}\right)
$$

Therefore, the heat flux and wall temperature are strongly coupled. Formula (12) can be written in the form of equivalent thermal resistance according to the heat transfer direction as follows:

$$
q=\frac{T_{a w}-T_{w g}}{1 / h_{g}}=\frac{T_{w g}-T_{w c}}{1 / h_{p, e q}}=\frac{T_{w c}-T_{b}}{1 / h_{c, e q}}=\frac{T_{a w}-T_{b}}{1 / h_{g}+1 / h_{p, e q}+1 / h_{c, e q}}=\frac{T_{a w}-T_{b}}{R_{e q}}
$$

where $R_{e q}$ is the equivalent total thermal resistance.

The computational domain is shown in Figure 4. The size of the cooling channel is $3 \mathrm{~mm} \times 3 \mathrm{~mm}$, and the thicknesses of the ribs and walls are all $3 \mathrm{~mm}$. An entry section of 
$180 \mathrm{~mm}$ in length is included to ensure a fully developed channel flow, and an exit section of $180 \mathrm{~mm}$ is used to reduce the impact of the exit segment. The mass-flow-inlet boundary condition was applied for the inlet of kerosene, where mass flow rate and inlet temperature are specified. The pressure-outlet boundary condition is applied for the outlet of kerosene. According to the state equation of ideal gas, the total pressure of high-temperature gas can be determined by the mass flow rate, static pressure and total temperature. Therefore, the inlet of high-temperature gas is also set as mass flow inlet, where mass flow rate, static pressure and total temperature are specified. The outlet of high-temperature gas is set as pressure outlet. The gas heated surface and cooling channel walls are set as coupled walls, while other walls or surfaces are set as symmetry or adiabatic walls in order to match the actual physical process. The flowing direction of high-temperature gas is along the positive direction of $\mathrm{z}$-axis. The material of cooling panel is steel, and a constant thermal conductivity $20 \mathrm{~W} \cdot \mathrm{K}^{-1} \cdot \mathrm{m}^{-1}$ of steel is used for simulation. The complicated reaction in the combustor is not solved in the research, and uniform incoming flow of high-temperature gas is used for simulation. The mass fraction of high-temperature gas is $\mathrm{N}_{2}$ in $53.1 \%, \mathrm{O}_{2}$ in $23.3 \%, \mathrm{CO}_{2}$ in $14.6 \%$, and $\mathrm{H}_{2} \mathrm{O}$ in $9.0 \%$ for all cases.

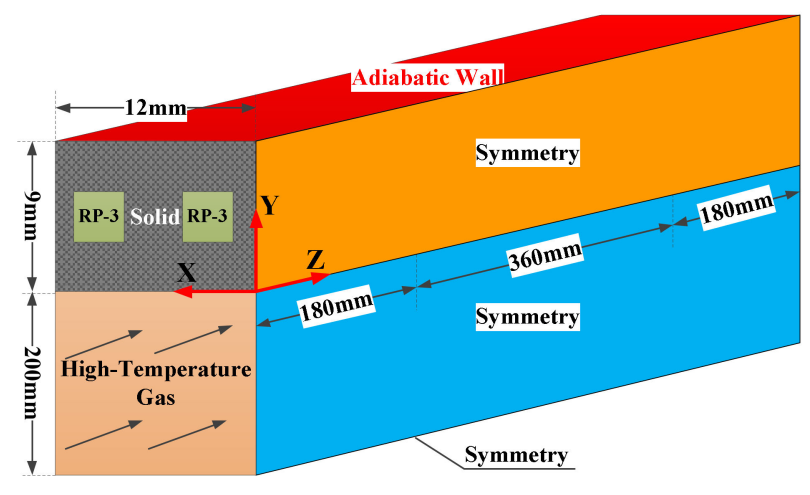

Figure 4. Computational domain.

The parameters of the simulation cases are listed in Table 1. $T_{\text {in }}$ is the inlet temperature of kerosene, $P_{c}$ is the pressure of kerosene, and $m_{c}$ is the mass flow rate of kerosene in a single cooling channel. $m_{g}$ is the mass flow rate of high-temperature gas, $T_{0}$ is the total temperature of high-temperature gas, and $P_{g, s}$ is the static pressure of high-temperature gas. The operating pressure is zero for all cases.

Table 1. Numerical parameters in different cases.

\begin{tabular}{ccccccccc}
\hline Case ID & $\boldsymbol{T}_{\boldsymbol{i n}} / \mathbf{K}$ & $\boldsymbol{P}_{\boldsymbol{c}} / \mathbf{M P a}$ & $\boldsymbol{m}_{\boldsymbol{c}} /(\mathbf{k g} / \mathbf{s})$ & $\boldsymbol{R}_{\boldsymbol{c}, \boldsymbol{i n}}$ & $\left.\boldsymbol{m}_{\boldsymbol{g}} / \mathbf{( k g} / \mathbf{s}\right)$ & $\boldsymbol{T}_{\mathbf{0}} / \mathbf{K}$ & $\boldsymbol{P}_{\boldsymbol{g}, \boldsymbol{s}} / \mathbf{k P a}$ & $\boldsymbol{M a}$ \\
\hline Case\#1 & 333 & 4 & 0.018 & 7200 & 1.2 & 1900 & 75 & 2.76 \\
Case\#2 & 333 & 4 & 0.018 & 7200 & 0.8 & 1900 & 50 & 2.76 \\
Case\#3 & 333 & 4 & 0.018 & 7200 & 1.6 & 1900 & 100 & 2.76 \\
Case\#4 & 333 & 4 & 0.018 & 7200 & 1.2 & 1600 & 75 & 2.60 \\
Case\#5 & 333 & 4 & 0.018 & 7200 & 1.2 & 2200 & 75 & 2.91 \\
Case\#6 & 333 & 4 & 0.018 & 7200 & 1.2 & 2500 & 75 & 3.03 \\
Case\#7 & 333 & 4 & 0.018 & 7200 & 1.2 & 2800 & 75 & 3.15 \\
Case\#8 & 333 & 3 & 0.018 & 7200 & 1.2 & 1900 & 75 & 2.76 \\
Case\#9 & 333 & 5 & 0.018 & 7200 & 1.2 & 1900 & 75 & 2.76 \\
Case\#11 & 333 & 4 & 0.006 & 2400 & 1.2 & 1900 & 75 & 2.76 \\
Case\#11 & 333 & 4 & 0.012 & 4800 & 1.2 & 1900 & 75 & 2.76 \\
Case\#12 & 333 & 4 & 0.024 & 9600 & 1.2 & 1900 & 75 & 2.76 \\
Case\#13 & 333 & 4 & 0.030 & 12000 & 1.2 & 1900 & 75 & 2.76 \\
\hline
\end{tabular}

The high-temperature gas contains several components. The ideal gas model is used to define the density of all the components. Two 4th-order polynomials as function of temperature are applied to calculate the specific heat of gas in temperature ranges of 
$300 \mathrm{~K}-1000 \mathrm{~K}$ and of $1000 \mathrm{~K}-5000 \mathrm{~K}$ respectively. The viscosity and thermal conductivity coefficient are calculated by kinetic theory. The properties of the mixed high-temperature gas are calculated through ideal gas mixing law.

The China no. 3 aviation kerosene RP-3 is used as coolant in this study. The thermophysical properties of RP-3 at supercritical pressures can be obtained by experimental measurements [33-35], or regarded as multi-component substitutions $[29,36]$ and calculated by the SUPERTRAPP program [37]. In this paper, a 10-component substitution model proposed by Zhong et al. [36] is used to calculate the physical properties of supercritical pressure kerosene. The thermophysical properties of the 10-component kerosene as function of temperature at different supercritical pressures are shown in Figure 5.

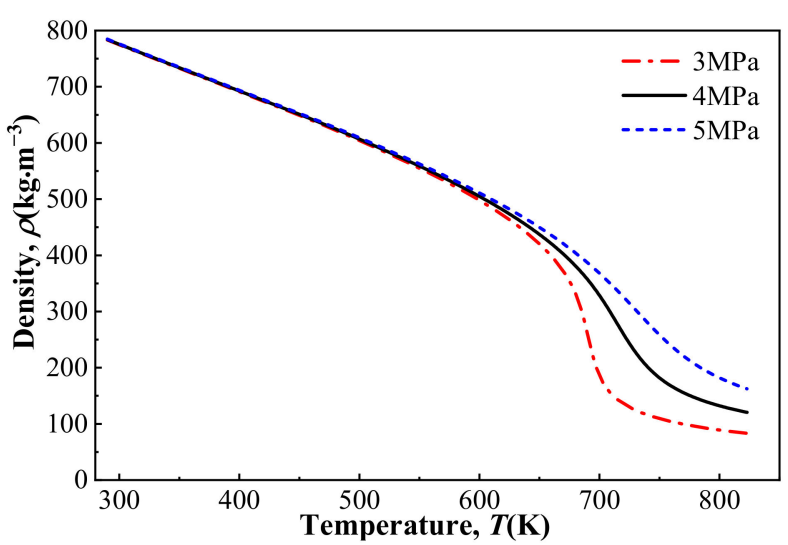

(a)

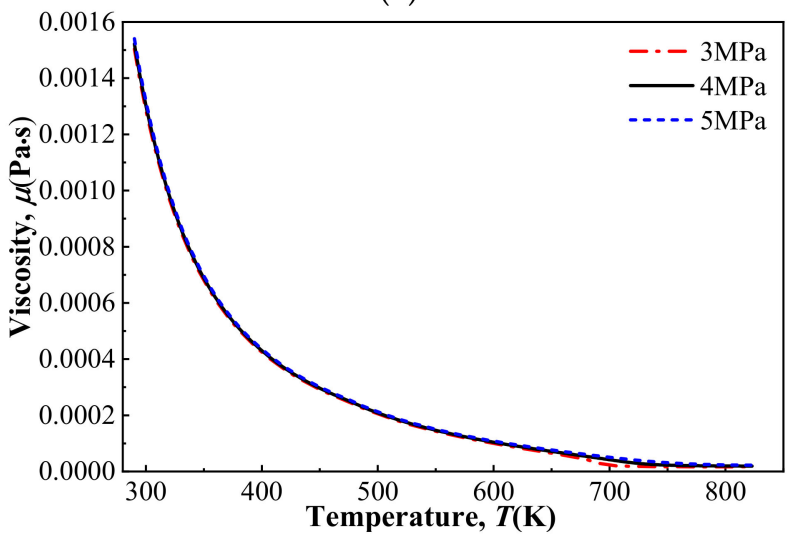

(c)

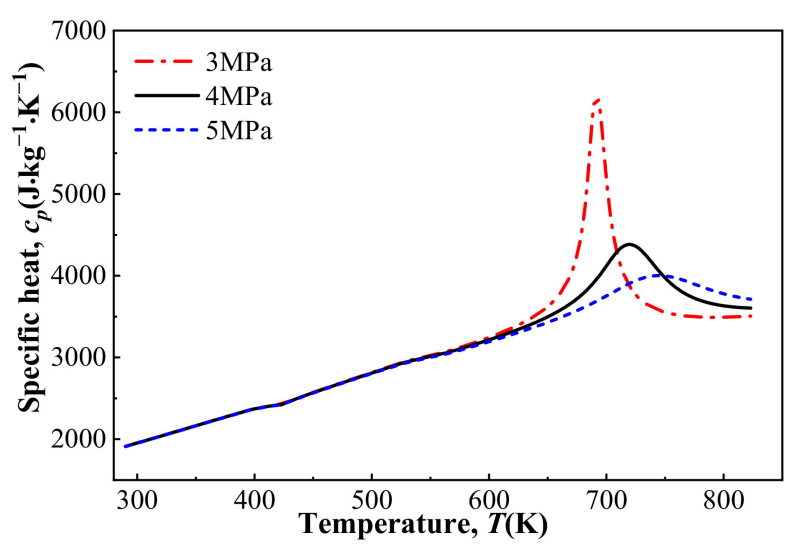

(b)

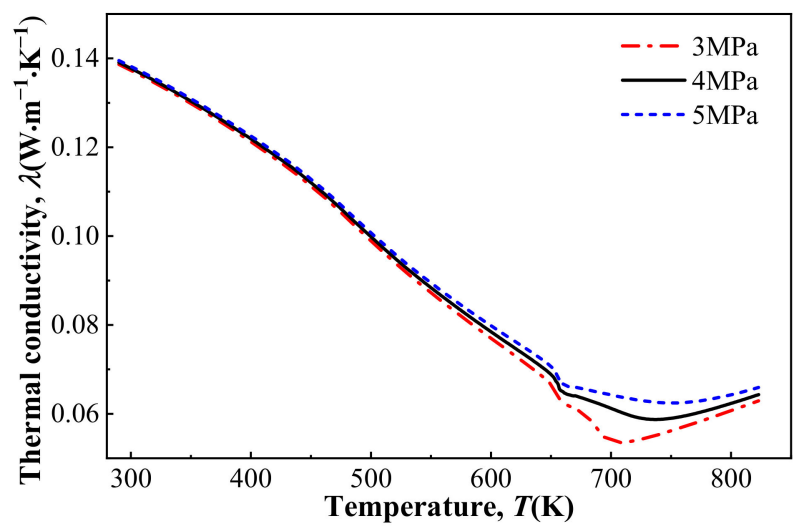

(d)

Figure 5. Thermophysical properties of 10-component kerosene as function of temperature at supercritical pressures: (a) Density (b) Specific heat (c) Viscosity (d) Thermal Conductivity.

\subsection{Validation}

To our best knowledge, there is still no detailed experimental data of the coupled heat transfer between high-temperature gas and regenerative cooling panel in published literatures that can be used for simulation validation. In order to verify the accuracy of the proposed method, the simulation and theoretical calculations of three-dimensional coupled heat transfer between high-temperature gas and cooling panel with no ribs inside are conducted. The physical model of the three-dimensional coupled heated transfer used for numerical validation is shown in Figure 6. For theoretical analysis and calculations, the heat transfer of high-temperature gas is calculated by the method recommended by Eckert [38] for high-speed flow. The heat conduction in the solid zone is calculated by Fourier's law. To take into account the property variations, the Sieder-Tate relation [39] is used to calculate the heat transfer of kerosene. The height of the channel is $2 \mathrm{~mm}$, and an equivalent hydraulic diameter $4 \mathrm{~mm}$ is used for theoretical calculations. The inlet 
conditions of high-temperature gas and kerosene in the validation simulation are consistent with Case\#1. The comparison of bulk temperature $T_{b}$ of kerosene, wall temperature $T_{w g}$ and heat flux $q_{g}$ at the gas heated surface between simulation and theoretical calculations is shown in Figure 7. Results indicated that there is no obvious difference of $T_{b}$ between simulation and theoretical calculations, and the distinction of $T_{w g}$ is less than $15 \mathrm{~K}$. Besides, the relative difference of $q_{g}$ between simulation and theoretical calculations is within 5\%. Therefore, the numerical method can be used to simulate the three-dimensional coupled heat transfer of regenerative cooling.

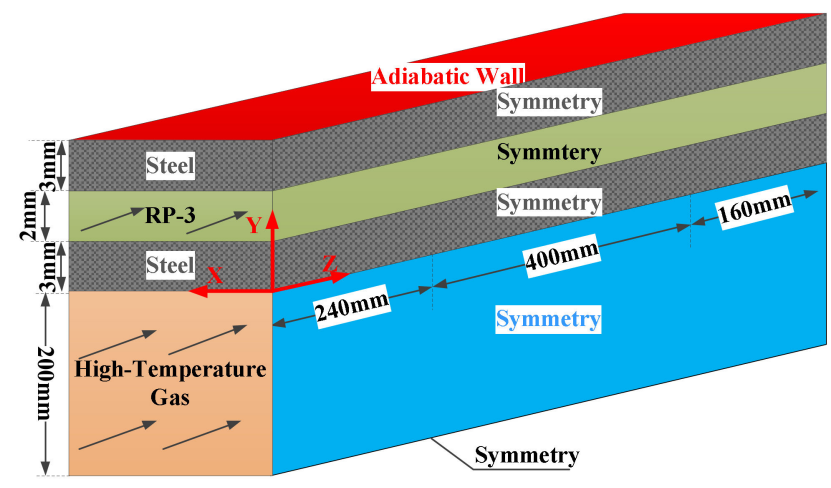

Figure 6. Physical model of the three-dimensional coupled heated transfer used for numerical validation.

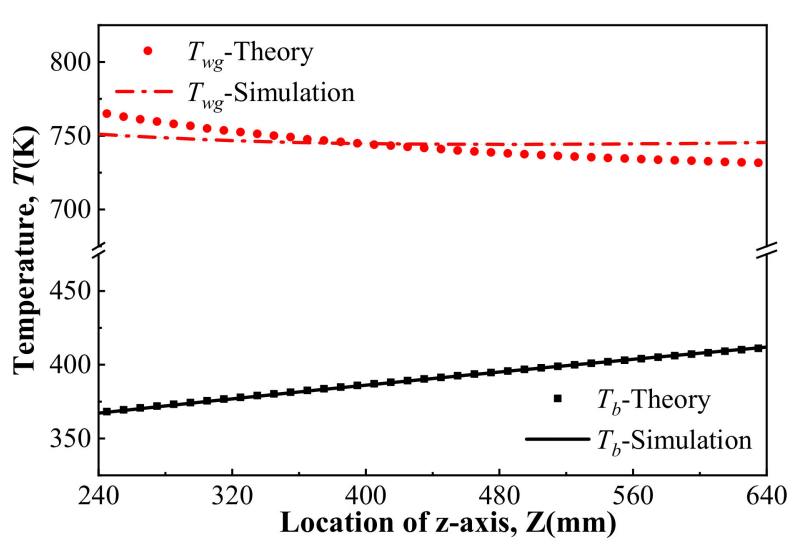

(a)

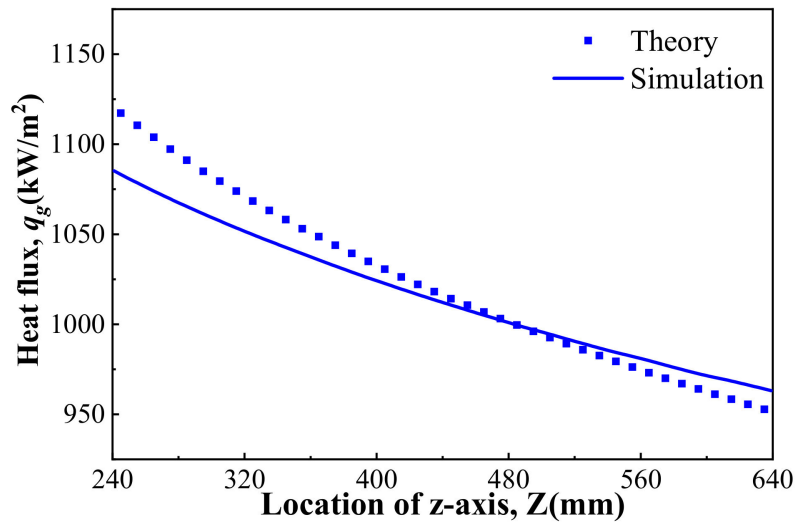

(b)

Figure 7. Comparison of $T_{b}, T_{w g}$ and $q_{g}$ between simulation and theoretical calculations: (a) Variation of $T_{b}$ and $T_{w g}$ (b) Variation of $q_{g}$.

\subsection{Mesh Sensitivity}

Case\#1 is chosen to test the mesh sensitivity with kerosene flowing along the positive direction of z-axis, and five different meshes are used for the test. The information of different meshes is listed in Table 2. $N_{c}$ is the number of elements in the kerosene zone, $N_{p}$ is the number of elements in the solid zone, $N_{g}$ is the number of elements in the gas zone, and $N_{t o t}$ is the total number of elements in the whole computational domain. 
Table 2. Grid division of different meshes.

\begin{tabular}{ccccc}
\hline Mesh ID & $N_{\boldsymbol{c}}$ & $N_{\boldsymbol{p}}$ & $N_{\boldsymbol{g}}$ & $N_{\text {tot }}$ \\
\hline Mesh\#1 & 324,000 & 180,000 & 576,000 & $1,080,000$ \\
Mesh\#2 & 576,000 & 405,000 & $1,080,000$ & $2,061,000$ \\
Mesh\#3 & $1,400,000$ & 630,000 & $1,680,000$ & $3,710,000$ \\
Mesh\#4 & $2,016,000$ & $1,120,000$ & $3,584,000$ & $6,720,000$ \\
Mesh\#5 & $3,584,000$ & $1,120,000$ & $4,032,000$ & $8,736,000$ \\
\hline
\end{tabular}

The heat flux $q_{g}$ at the centerline of the gas heated surface along the flow direction is shown in Figure 8. The simulation results of Mesh\#1 and Mesh\#2 are significantly different from those of Mesh\#3, Mesh\#4 and Mesh\#5, while the relative distinction of $q_{g}$ in Mesh\#3, Mesh\#4 and Mesh\#5 is within $0.5 \%$. Therefore, Mesh\#3 is sufficient for numerical simulations in this study. The grid division at the cross section of the computational domain in Mesh\#3 is shown in Figure 9.

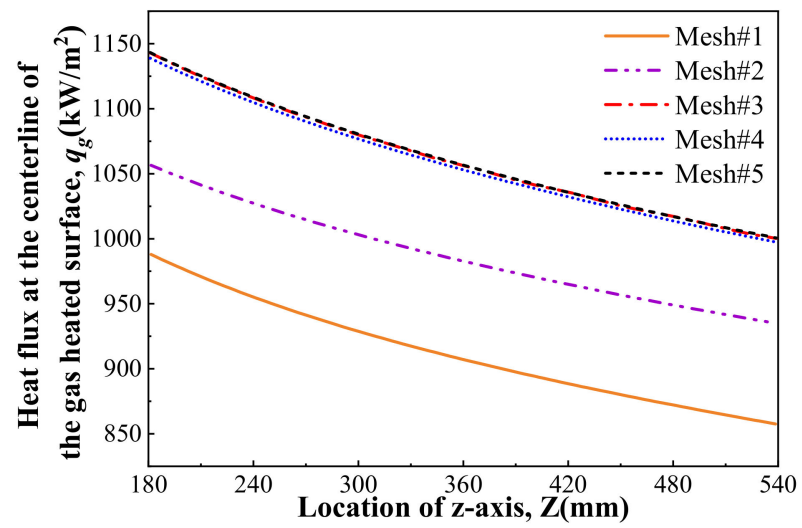

Figure 8. Variation of $q_{g}$ at the centerline of the gas heated surface for mesh sensitivity test in Case\#1.

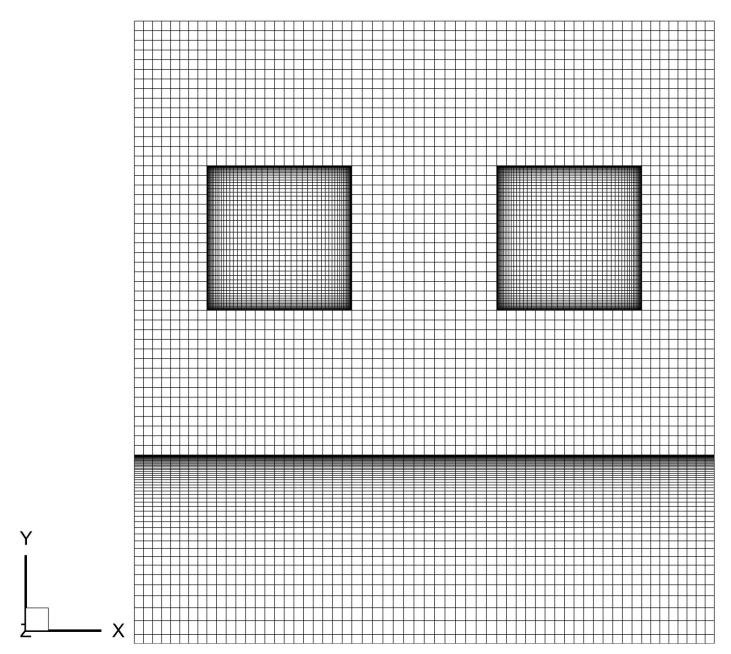

Figure 9. Grid division of the cross section in Mesh\#3.

\section{Results and Discussion}

\subsection{Primary Characteristics of Regenerative Cooling}

The primary characteristics of Case\#1 with kerosene flowing along the positive direction of $\mathrm{z}$-axis are discussed in this section.

The contour graph of wall temperature $T_{w g}$ and heat flux $q_{\mathrm{g}}$ at the gas heated surface of the cooling panel is shown in Figure 10a,b, respectively. It can be seen that $T_{w g}$ first declines and then rises along the flow direction. The variation of $T_{w g}$ is less than $10 \mathrm{~K}$ at 
the gas heated surface, and the relative difference of $T_{\text {wg }}$ is within $2 \%$. The heat flux $q_{\mathrm{g}}$ of the gas heated surface is in the order of $10^{6} \mathrm{~W} / \mathrm{m}^{2}$. It is obvious that $q_{\mathrm{g}}$ decreases along the whole flow direction. The decline of $q_{\mathrm{g}}$ is more than $140 \mathrm{~kW} / \mathrm{m}^{2}$, which means that $q_{\mathrm{g}}$ dropped as much as $13 \%$ along the flow direction. Besides, the difference of $T_{w g}$ and $q_{\mathrm{g}}$ in $x$ direction is very small, thus the temperature $T_{w g}$ and heat flux $q_{\mathrm{g}}$ at the centerline of the gas heated surface is used for analysis instead of contour graphs in the rest of the article.

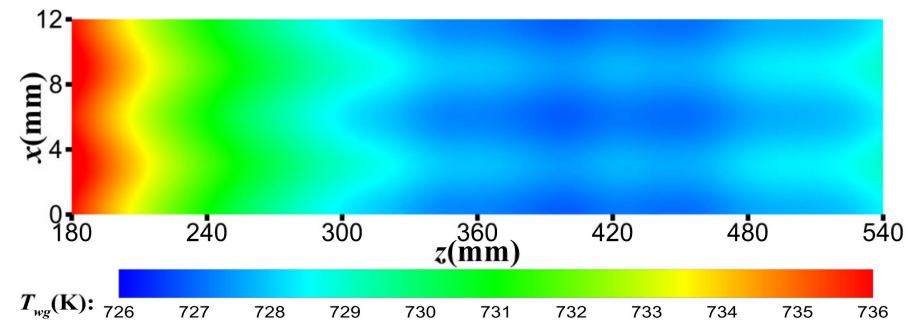

(a)

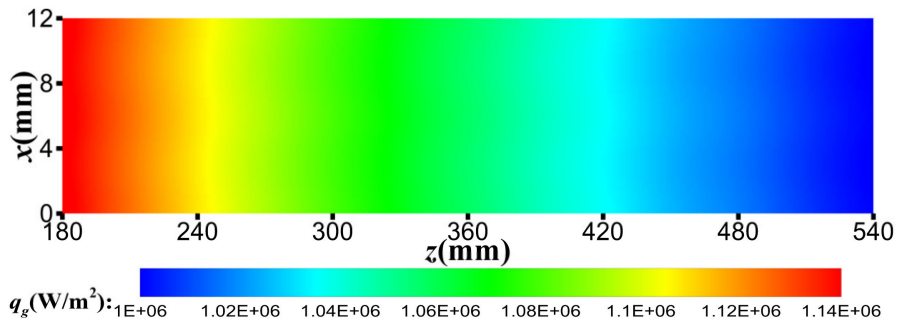

(b)

Figure 10. Distribution of $T_{w g}$ and $q_{g}$ of the gas heated surface in Case\#1: (a) Distribution of $T_{w g}(\mathbf{b})$ Distribution of $q_{g}$.

Since the flow and heat transfer is strongly coupled according to Equation (12), the analysis of $T_{w g}$ and $q_{\mathrm{g}}$ should be combined with the flow and heat transfer characteristics of high-temperature gas and kerosene. The loss in stagnation temperature $T_{0}$ of hightemperature gas is very small along the flow direction, thus the adiabatic wall temperature $T_{a w}$ can be considered as constant. Since the variation of wall temperature $T_{w g}$ is less than $10 \mathrm{~K}$, the decline of $q_{g}$ along the flow direction is mainly caused by the decrease of $h_{g}$. A reasonable assumption is that the decrease of $h_{g}$ along the flow direction is mainly caused by the development of boundary layer at the gas heated surface. The assumption can be confirmed by the velocity distribution of high-temperature gas in Figure 11. Since the thickness of boundary layer keeps increasing along the flow direction, the heat transfer resistance between gas and cooling panel increases, which leads to the decrease of $h_{g}$ and $q_{g}$ along the flow direction.

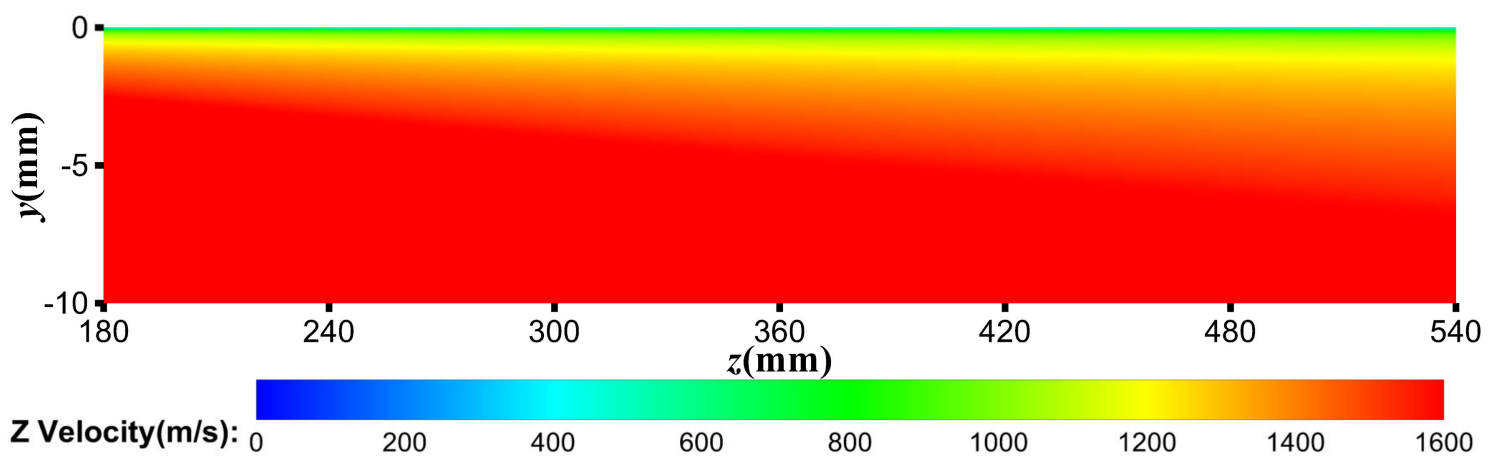

Figure 11. Velocity distribution of high-temperature gas.

As kerosene flowing through the cooling channel and being heated, the bulk temperature $T_{b}$ of kerosene increases along the flow direction. The density and viscosity of kerosene decreases, the velocity and Reynolds number of kerosene increases, which promotes the heat transfer coefficient $h_{c}$ of kerosene in the cooling channels. According to Equation (12), the reduction of $h_{g}$ and the increase of $h_{c}$ would lead to the decline of $T_{w g}$, while the increase of $T_{b}$ would lead to the rise of $T_{w g}$. The wall temperature $T_{w g}$ first declines and then rises along the flow direction, which is a result due to the combination of these two factors.

The temperature of the cooling panel and kerosene at different locations of the cross section is shown in Figure 12. It is obvious that there is a significant stratification of temperature in the cooling panel near the gas heated surface. The distance between 
different temperature layers in this zone is almost the same, indicating that the temperature gradient and heat flux of the cooling panel can be considered as uniform near the gas heated surface. There is no obvious stratification of temperature in the cooling panel close to the adiabatic wall, which means that the heat flux in this zone is small, and the temperature stratification in this zone gradually diminishes along the flow direction. There is also a significant stratification of temperature in the cooling channels. As kerosene flowing through the cooling channels and being heated, the kerosene near the gas heated wall is of higher temperature, while kerosene of lower temperature is gathered in the zone away from the gas heated wall.

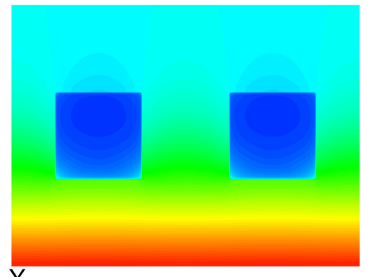

$Z=180 \mathrm{~mm}$

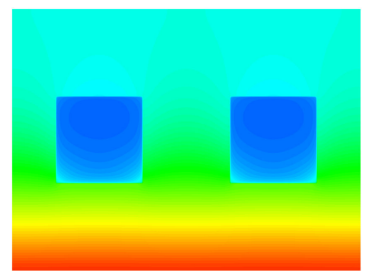

$\mathrm{Z}=300 \mathrm{~mm}$

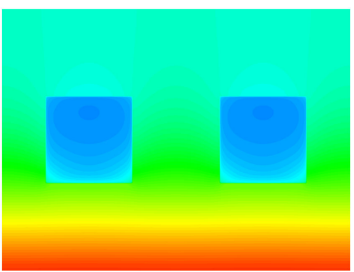

$\mathrm{Z}=420 \mathrm{~mm}$

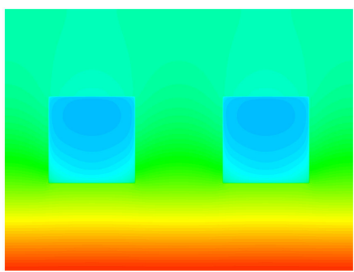

$\mathrm{Z}=540 \mathrm{~mm}$ $T(\mathrm{~K}):$

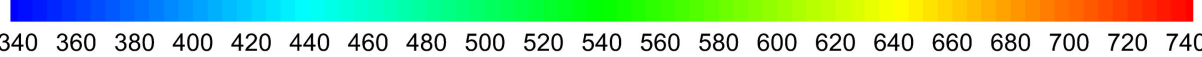

Figure 12. Temperature distribution of the cooling panel and kerosene in the cross sections.

\subsection{Influencing Factors of Coupled Heat Transfer}

The material and configuration of the cooling panel in an engine generally remains unchanged, thus the coupled heat transfer is mainly affected by the flowing direction of coolant as well as the flowing parameters of gas and coolant. The influencing factors of coupled heat transfer are studies and discussed in the following sections.

\subsubsection{Flowing Direction of Kerosene}

The bulk temperature $T_{b}$ and heat transfer coefficient $h_{c}$ of kerosene in the cooling channels would change with the flowing direction of kerosene, leading to the change of wall temperature $T_{w g}$ and heat flux $q_{\mathrm{g}}$ of the gas heated surface.

The coupled heat transfer between high-temperature gas and cooling panel with kerosene flowing along the negative direction of $\mathrm{z}$-axis was conducted, in which the flowing parameters of high-temperature gas and kerosene are consistent with Case\#1. For kerosene flowing along the positive direction of $\mathrm{z}$-axis, the flow is defined as cocurrent flow. For kerosene flowing along the negative direction of $\mathrm{z}$-axis, the flow is defined as counter flow. The variation of $T_{b}$ and $h_{c}$ along the z-axis in cocurrent and counter flow is shown in Figure 13. It can be seen that for cocurrent flow, $T_{b}$ and $h_{c}$ rises along the positive direction of z-axis, while for counter flow, $T_{b}$ and $h_{c}$ rises along the negative direction of z-axis.

The variation of wall temperature $T_{w g}$ and heat flux $q_{g}$ at the centerline of the gas heated surface in cocurrent and counter flow is shown in Figure 14. It is obvious that for counter flow, $T_{w g}$ and $q_{g}$ both declines along the flow direction of gas. The variation of $T_{w g}$ in counter flow is more drastic, while the variation of $q_{g}$ in counter flow is smaller. Besides, the peak of $T_{w g}$ in counter flow is much higher than that in cocurrent flow. Compared with counter flow, cocurrent flow can better meet the requirements of thermal protection. Therefore, the flowing direction of high-temperature gas and kerosene are both along the positive direction of $z$-axis in the subsequent study. 


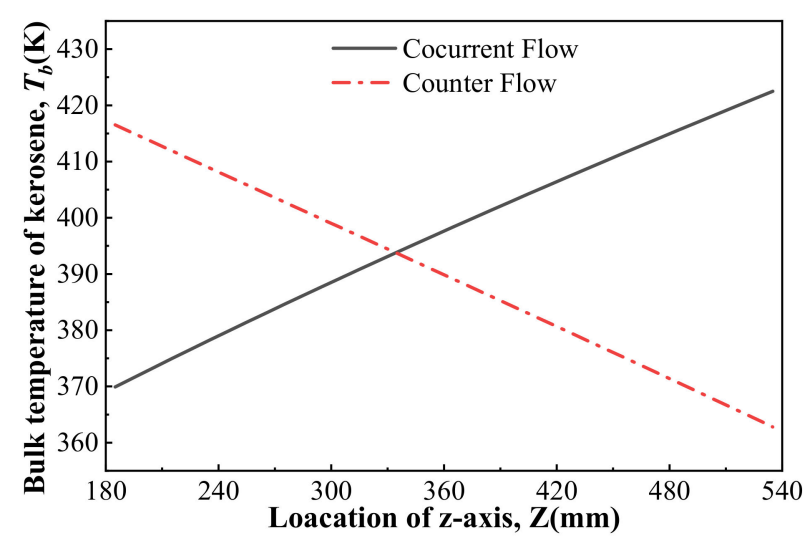

(a)

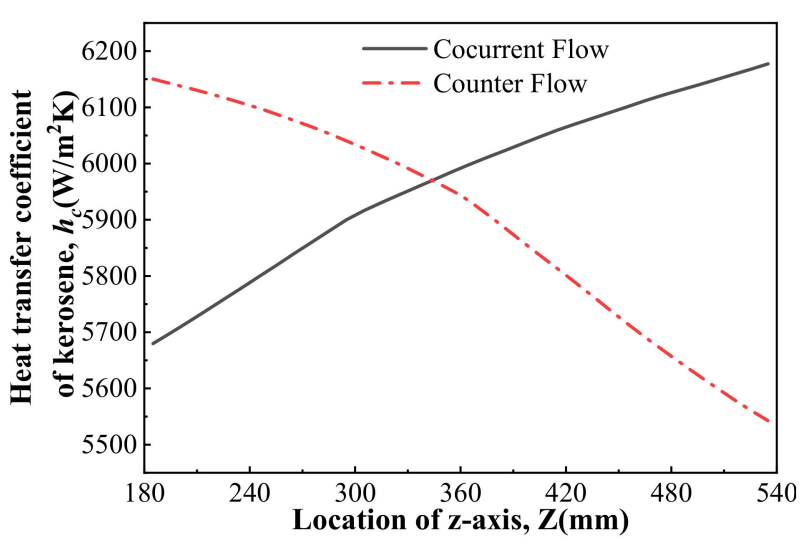

(b)

Figure 13. Variation of $T_{b}$ and $h_{c}$ along the z-axis in cocurrent and counter flow: $(\mathbf{a}) T_{b}(\mathbf{b}) h_{c}$.

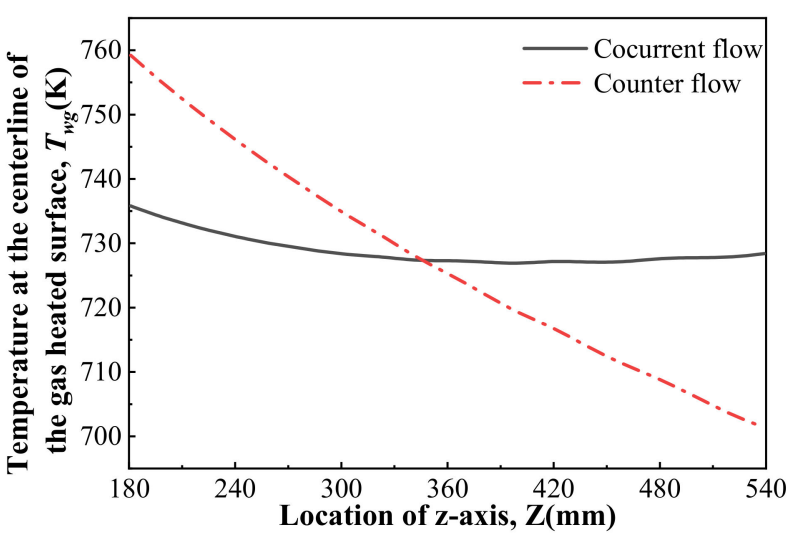

(a)

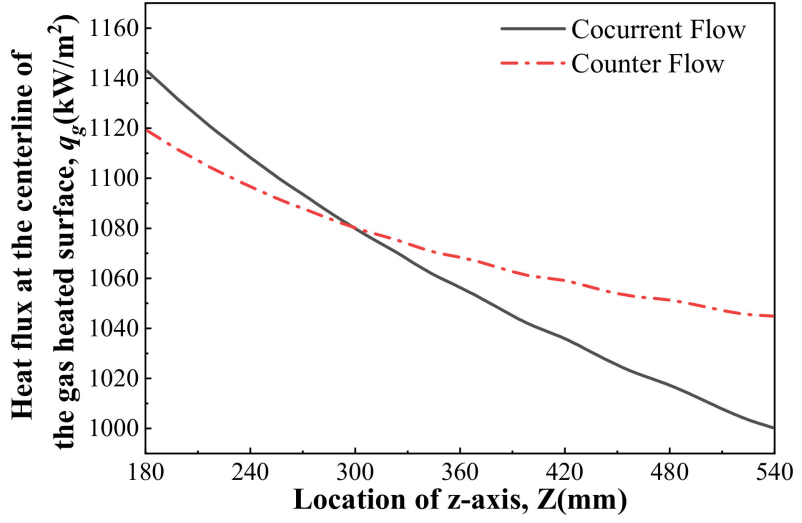

(b)

Figure 14. Variation of wall temperature $T_{w g}$ and heat flux $q_{g}$ at the centerline of the gas heated surface in cocurrent and counter flow: (a) $T_{w g}(\mathbf{b}) q_{g}$.

\subsubsection{Flowing Parameters of High-Temperature Gas}

The flowing parameters of high-temperature gas are investigated in this section.

The heat transfer between regenerative cooling panel and high-temperature gas of different static pressure is conducted in Case\#2 and Case\#3. Compared with Case\#1, the static pressure and mass flow rate of gas is changed in Case\#2 and Case\#3, while the total temperature, Mach number and static temperature remains unchanged. The variation of wall temperature $T_{w g}$ and heat flux $q_{g}$ at the centerline of the gas heated surface in these cases is shown in Figure 15. The results showed that $T_{w g}$ and $q_{g}$ increase significantly with the static pressure of high-temperature gas. Since the inlet total temperature and Mach number of gas are the same in Case\#1, Case\#2 and Case\#3, the adiabatic wall temperature $T_{\mathrm{aw}}$ is almost the same in these cases. Therefore, according to Equation (9), the increase of $T_{w g}$ and $q_{g}$ is mainly caused by the increase of $h_{\mathrm{g}}$. The density and mass flow rate of gas increases with static pressure, the Reynolds number and heat transfer coefficient $h_{\mathrm{g}}$ of gas also increases with static pressure. Therefore, it can be deduced from Equations (12) and (13) that $T_{w g}$ and $q_{g}$ will also increase with the static pressure of gas. When the static pressure of gas increases from $50 \mathrm{kPa}$ to $75 \mathrm{kPa}$, the average increase of $T_{w g}$ and $q_{g}$ is $85.2 \mathrm{k}$ and $255.5 \mathrm{~kW} / \mathrm{m}^{2}$, respectively. When the static pressure of gas increased from $75 \mathrm{kPa}$ to $100 \mathrm{kPa}$, the average increase of $T_{w g}$ is $71.7 \mathrm{k}$, and the average increase of $q_{g}$ is $210.6 \mathrm{~kW} / \mathrm{m}^{2}$. 


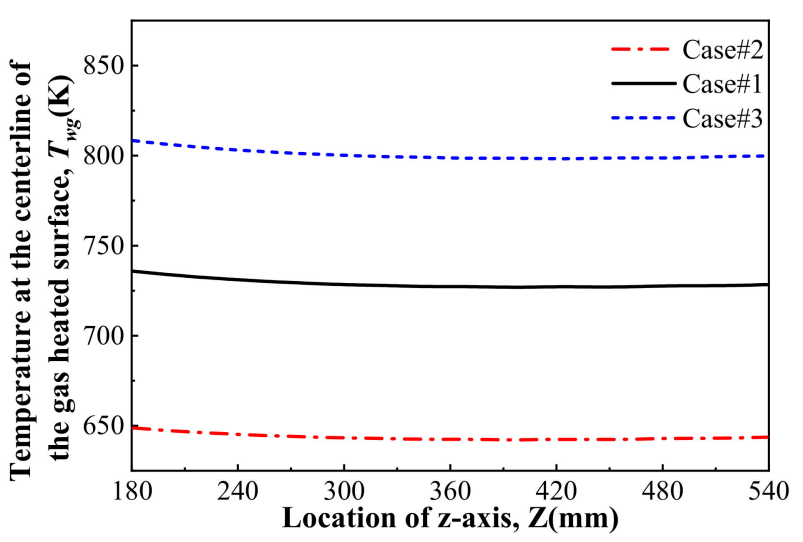

(a)

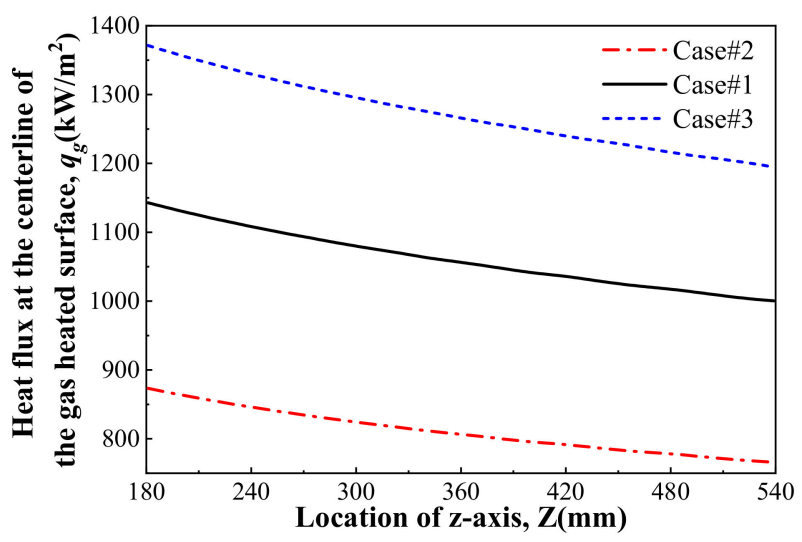

(b)

Figure 15. Variation of $T_{w g}$ and $q_{g}$ at the centerline of the gas heated surface with static pressures of gas: (a) $T_{w g}(\mathbf{b}) q_{g}$.

The heat transfer coefficient $h_{g}$ and Nusselt number $N u_{g}$ of high-temperature gas at different static pressures is shown in Figure 16. As is shown in Figure 16a, $h_{g}$ increases with the static pressure of high-temperature gas, and declines along the flow direction. For static pressure of $50 \mathrm{kPa}, 75 \mathrm{kPa}$ and $100 \mathrm{kPa}$, the decline of $h_{g}$ along the flow direction is $12.7 \%, 13.1 \%$ and $13.6 \%$ respectively, which means the decline of $h_{g}$ along the flow direction increases with the static pressure of gas. The main reason may be that the density and viscosity of gas increases with the static pressure, which promotes the development of boundary layer, leading to a larger decline of $h_{g}$. Figure $16 \mathrm{~b}$ indicates that $N u_{g}$ increases with the static pressure of gas. Besides, it can be seen that $N u_{g}$ increases along the flow direction, and the increment of $N u_{g}$ along the flow direction increases with the rise of static pressure.

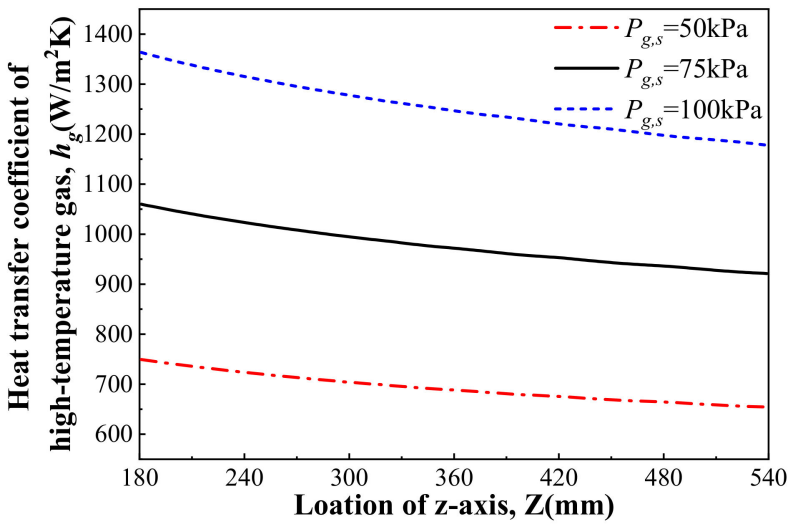

(a)

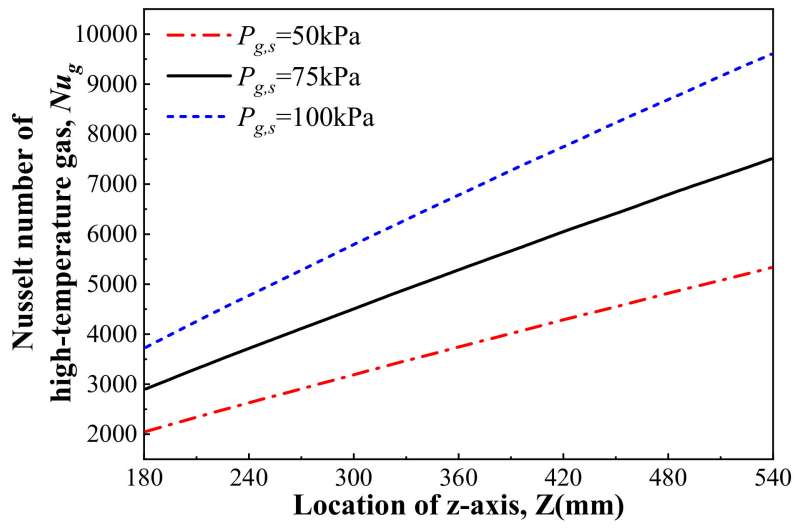

(b)

Figure 16. Variation of $h_{g}$ and $N u_{g}$ with static pressures of gas (a) $h_{g}(\mathbf{b}) N u_{g}$.

The heat transfer between regenerative cooling panel and high-temperature gas of different total temperature is conducted in Case\#4 to Case\#7. Compared with Case\#1, the total temperature of gas is changed in Case\#4 to Case\#7, while the mass flow rate and static pressure remains unchanged. The variation of wall temperature $T_{w g}$ and heat flux $q_{g}$ at the centerline of the gas heated surface in these cases is shown in Figure 17. The results showed that $T_{w g}$ and $q_{g}$ almost increases linearly with the increase of $T_{0}$. The rise of $T_{w g}$ is about $72 \mathrm{~K}$ and the rise of $q_{g}$ is about $210 \mathrm{~kW} / \mathrm{m}^{2}$ for every $300 \mathrm{~K}$ increase of $T_{0}$. The main reason is that the adiabatic wall temperature $T_{\text {aw }}$ increases with $T_{0}$, and according to Equations (12) and (13), this will lead to the rise of $T_{w g}$ and $q_{g}$. 


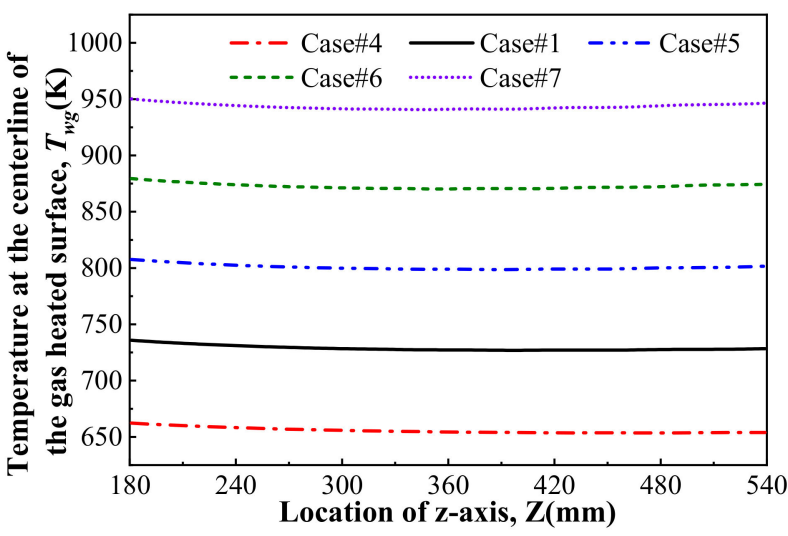

(a)

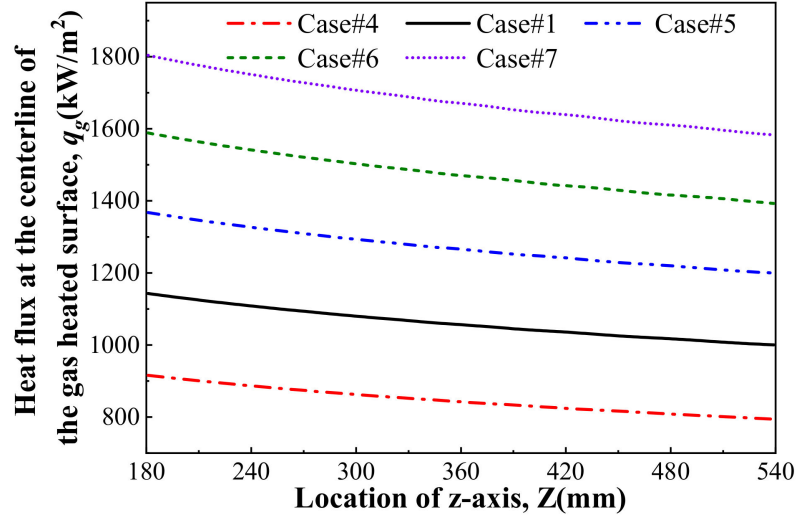

(b)

Figure 17. Variation of $T_{w g}$ and $q_{g}$ at the centerline of the gas heated surface with total temperatures of gas: (a) $T_{w g}(\mathbf{b}) q_{g}$.

The heat transfer coefficient $h_{g}$ and Nusselt number $N u_{g}$ of high-temperature gas at different total temperatures along the flow direction is shown in Figure 18. The relative distinction of $h_{g}$ at different total temperature is less than $2 \%$. The velocity and viscosity of the gas increases with the rise of $T_{0}$, while the density of gas decreases with that, leading to a slight decrease in Reynolds number, which would lead to a small drop of $h_{g}$. However, the thermal conductivity of the gas increases slightly with the rise of $T_{0}$, which would lead to a small rise of $h_{\mathrm{g}}$. Therefore, the heat transfer coefficient $h_{g}$ of high-temperature gas is almost the same at different total temperature. Figure $18 \mathrm{~b}$ indicates that $N u_{g}$ decreases with the rise of $T_{0}$. Besides, it can be seen that $N u_{g}$ increases along the flow direction, and the increment of $N u_{g}$ along the flow direction decreases with the rise of $T_{0}$.

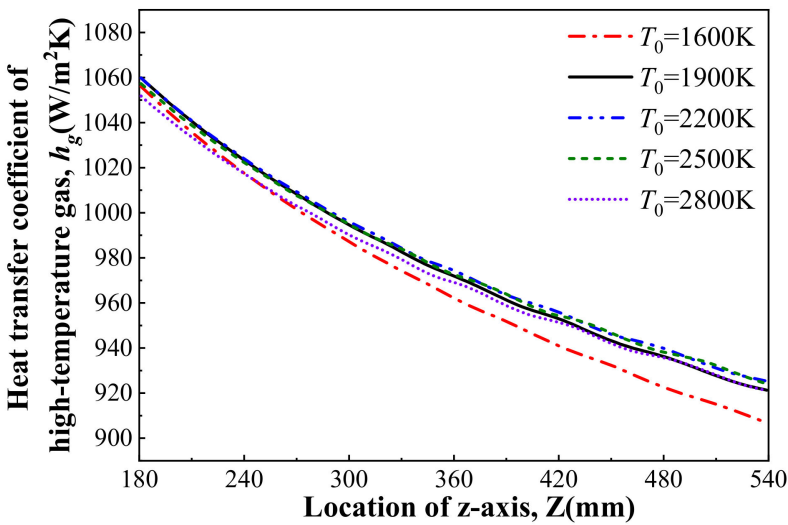

(a)

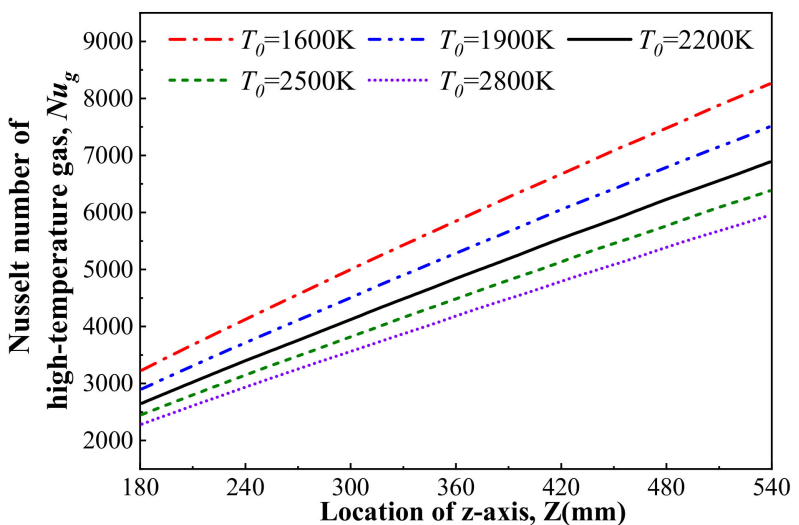

(b)

Figure 18. Variation of $h_{g}$ and $N u_{g}$ with total temperatures of gas (a) $h_{g}(\mathbf{b}) N u_{g}$.

\subsubsection{Flowing Parameters of Kerosene}

The flowing parameters of kerosene are investigated in this section.

Case\#8 and Case\#9 are conducted to study the influence of supercritical pressure of kerosene. Compared with Case\#1, the supercritical pressure of kerosene in the cooling channels is changed in Case\#8 and Case\#9, while the mass flow rate and inlet temperature remain unchanged. The variation of wall temperature $T_{w g}$ and heat flux $q_{g}$ at the centerline of the gas heated surface in these cases is shown in Figure 19. The results showed that both $T_{w g}$ and $q_{g}$ are almost the same in these cases. The temperature of kerosene in the cooling channels is below $600 \mathrm{~K}$ in Case\#1, Case\#8 and Case\#9. According to Figure 5, the difference of thermophysical properties of kerosene at different supercritical pressures can 
be neglected when temperature is below $600 \mathrm{~K}$. Therefore, the flow and heat transfer of kerosene in the cooling channels are almost the same at different supercritical pressures, and the difference in $T_{w g}$ and $q_{g}$ can be neglected.

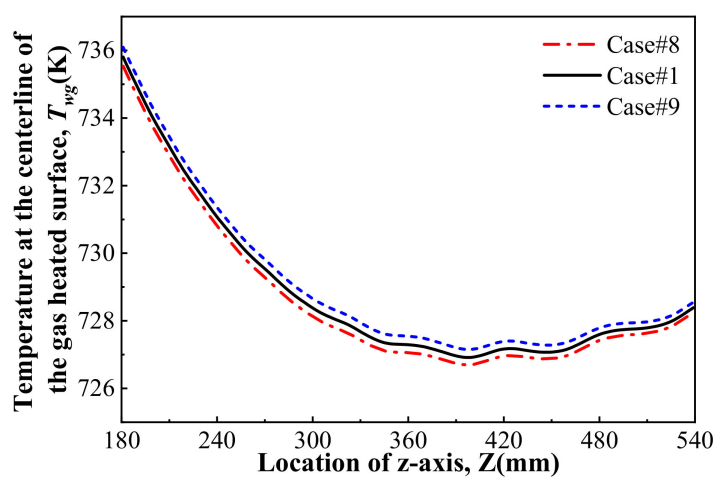

(a)

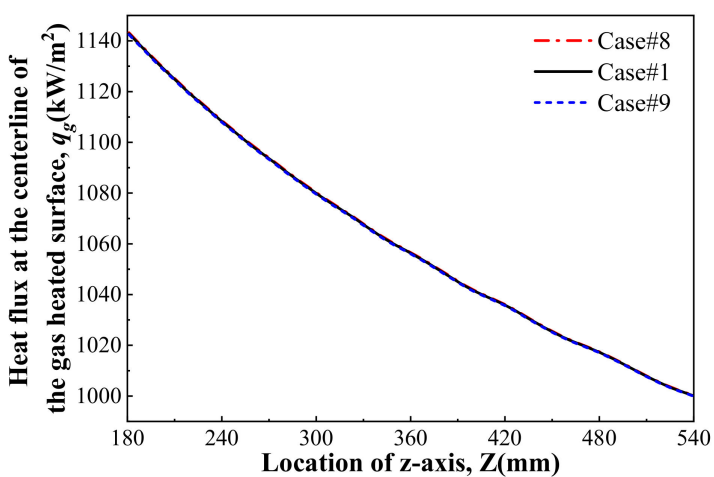

(b)

Figure 19. Variation of $T_{w g}$ and $q_{g}$ at the centerline of the gas heated surface with pressure of kerosene: (a) $T_{w g}(\mathbf{b}) q_{g}$.

Case\#10 to Case\#13 are conducted to study the influence of mass flow rate of kerosene. Compared with Case\#1, the mass flow rate of kerosene is changed in Case\#10 to Case\#13, while the inlet temperature and pressure of kerosene remains unchanged. The variation of wall temperature $T_{w g}$ and heat flux $q_{g}$ at the centerline of the gas heated surface in these cases is shown in Figure 20. The variation of bulk temperature $T_{b}$, heat transfer coefficient $h_{c}$ and Nusselt number $N u_{c}$ in the cooling channels is shown in Figure 21. The results showed that $q_{g}$ rises with the increases of mass flow rate of kerosene, while $T_{w g}$ declines with that. The increase in mass flow rate of kerosene promotes the Reynolds number and heat transfer coefficient $h_{c}$ of kerosene in the cooling channels, which reduces the total heat resistance and promotes the overall heat transfer. It can be seen from Figure 21 that for constant increment of kerosene, the variation of $T_{b}$ and $h_{c}$ declines with the mass flow rate of kerosene. Therefore, for constant increment of kerosene, the variation of $T_{w g}$ and $q_{g}$ also decreases with the mass flow rate of kerosene. Besides, the results also showed that the region where $T_{w g}$ rises along the flow direction decreases with the mass flow rate of kerosene. The main reason is that the bulk temperature $T_{b}$ of kerosene rises more slowly along the flow direction at larger mass flow rate of kerosene. Figure 21c indicates that $N u_{c}$ increases with the increase of mass flow rate of kerosene. Besides, it can be seen that $N u_{c}$ increases along the flow direction, and the increment of $N u_{c}$ along the flow direction decreases with the increase of mass flow rate of kerosene.

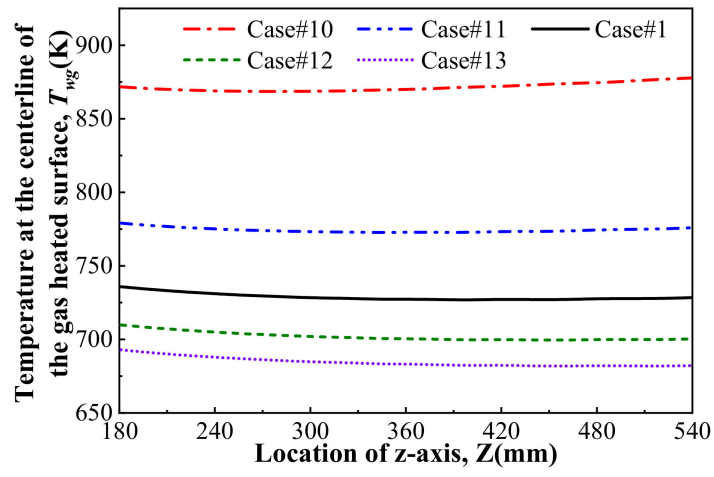

(a)

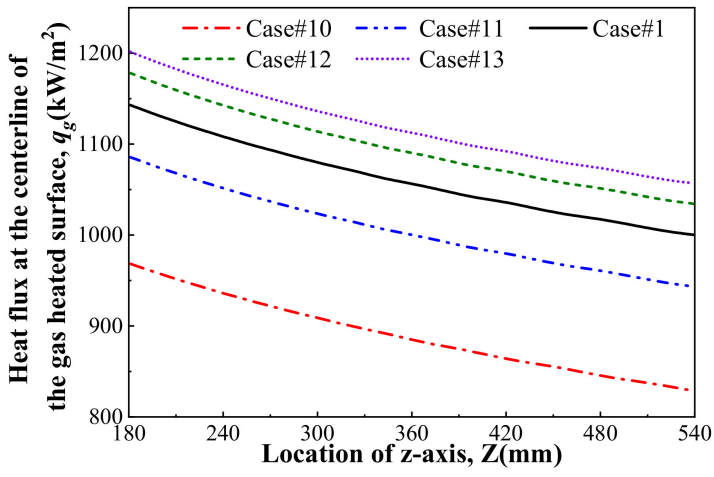

(b)

Figure 20. Variation of $T_{w g}$ and $q_{g}$ at the centerline of the gas side wall with mass flow rate of kerosene: (a) $T_{w g}(\mathbf{b}) q_{g}$. 


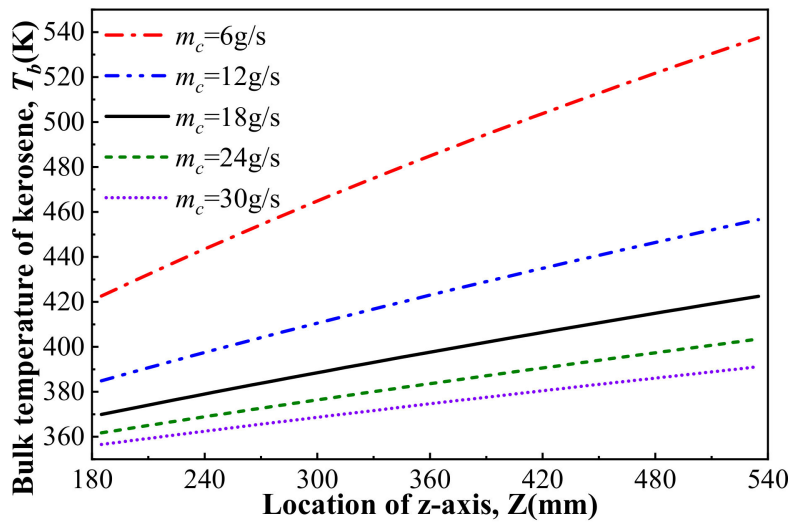

(a)

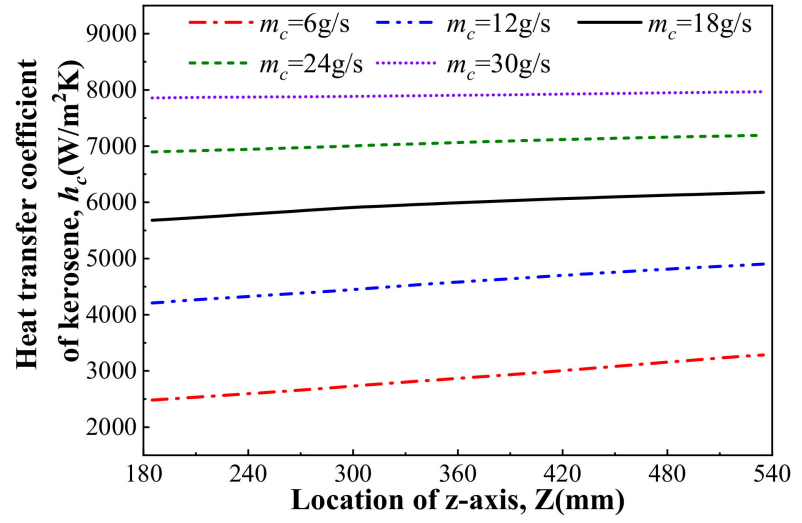

(b)

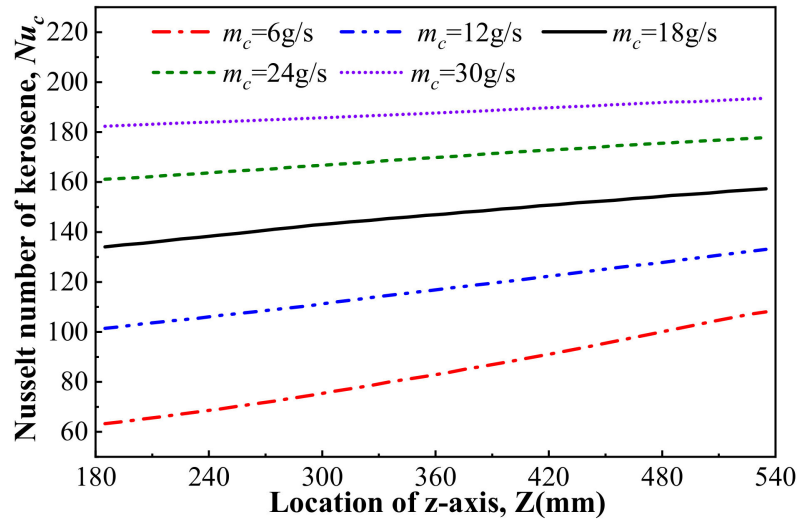

(c)

Figure 21. Variation of $T_{b}, h_{c}$ and $N u_{c}$ with mass flow rate of kerosene: (a) $T_{b}$ (b) $h_{c}$ (c) $N u_{c}$.

\section{Conclusions}

Regenerative cooling is crucial for the thermal protection of scramjet engines. Therefore, the three-dimensional coupled heat transfer between high temperature gas and regenerative cooling panel with kerosene of supercritical pressure flowing in the cooling channels was numerically investigated in this paper. Compared with other research, the heat convection of high-temperature gas in the combustor, the heat conduction in the cooling panel and heat convection of kerosene in the cooling channels were solved simultaneously in the present study. The temperature and heat flux of the gas heated surface are obtained, and the influencing factors of regenerative cooling were also investigated.

The heat flux of the gas heated surface is found to be in the order of $10^{6} \mathrm{~W} / \mathrm{m}^{2}$ at the present investigation conditions. The temperature of the gas heated surface in cocurrent flow first declines and then rises along the flow direction of gas, while it declines along the flow direction of gas in counter flow. The temperature variation of the gas heated surface in counter flow is more drastic, while the heat flux variation in counter flow is smaller. Compared with counter flow, cocurrent flow can better meet the requirements of thermal protection because the temperature peak of the gas heated surface in counter flow is much higher than that in cocurrent flow.

Parametric investigations indicated that the temperature and heat transfer of the gas heated surface are greatly influenced by the flowing parameters of high-temperature gas and mass flow rate of kerosene, while they are almost unaffected by the supercritical pressure of kerosene in the cooling channels. The heat transfer coefficient of high-temperature gas is almost the same at different total temperature, while Nusselt number of it decreases with total temperature. Although the heat transfer coefficient of kerosene increases along the flow direction in cocurrent flow, the heat flux of the gas heated surface decreases along the flow direction due to the development of boundary layer at the gas heated surface. 
Since the three-dimensional coupled heat transfer of regenerative cooling is realized in the research, the proposed method can be used to study the influence of panel configuration and results can be used to guide the structural design and optimization. Besides, the proposed method can be improved for further investigation of the semi-active (or semipassive) cooling as well as film cooling in the future.

Author Contributions: Methodology, J.Z.; project administration, Y.P.; numerical simulations and original draft, J.H. and N.W.; writing - review and editing, N.W. and J.H. All authors have read and agreed to the published version of the manuscript.

Funding: This research was funded by National Natural Science Foundation of China (11572346) and Natural Science Foundation of Hunan Province, China (2020JJ4666).

Data Availability Statement: Data is contained within the article.

Acknowledgments: The authors would like to express their special thanks to National Supercomputing Center in Changsha for software and resource supporting.

Conflicts of Interest: The authors declare no conflict of interest.

\section{Abbreviations}

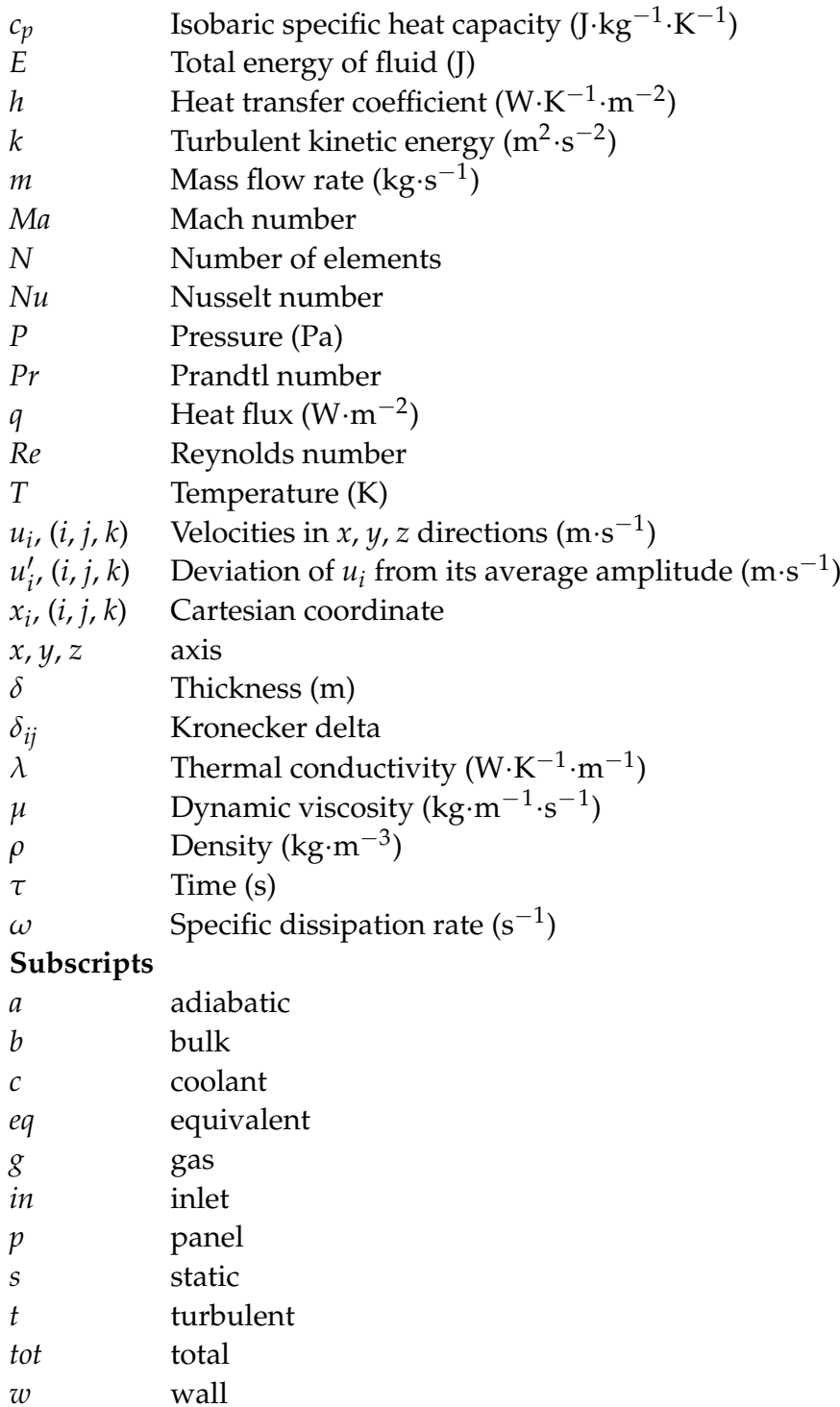




\section{References}

1. Bertin, J.J.; Cummings, R.M. Fifty years of hypersonics: Where we've been, where we're going. Prog. Aerosp. Sci. 2003, 39, 511-536. [CrossRef]

2. Zhang, S.L.; Li, X.; Zuo, J.Y.; Qin, J.; Cheng, K.L.; Feng, Y.; Bao, W. Research progress on active thermal protection for hypersonic vehicles. Prog. Aerosp. Sci. 2020, 119, 100646. [CrossRef]

3. Zhu, Y.H.; Wei, P.; Xu, R.N.; Jiang, P.X. Review on active thermal protection and its heat transfer for airbreathing hypersonic vehicles. Chin. J. Aeronaut. 2018, 31, 1929-1953. [CrossRef]

4. Zhang, S.L.; Qin, J.; Zhou, W.X.; Bao, W. Review on regenerative cooling for hypersonic propulsion. J. Propuls. Technol. 2018, 39, 23-36. (In Chinese)

5. Kilkovský, B. Review of design and modeling of regenerative heat exchangers. Energies 2020, 13, 759. [CrossRef]

6. Gou, J.J.; Chang, Y.; Yan, Z.W.; Chen, B.; Gong, C.L. The design of thermal management system for hypersonic launch vehicles based on active cooling networks. Appl. Therm. Eng. 2019, 159, 113938. [CrossRef]

7. Kennedy, P.J.; Donbar, J.M.; Trelewicz, J.R.; Gouldstone, C.; Longtin, J.P. Heat flux measurements in a scramjet combustor using direct write technology. In Proceedings of the 17th AIAA International Space Planes and Hypersonic Systems and Technologies Conference, San Francisco, CA, USA, 11-14 April 2011.

8. Trelewicz, J.R.; Longtin, J.P.; Gouldstone, C.; Kennedy, P.J.; Donbar, J.M. Heat flux measurements in a scramjet combustor using embedded direct-write sensors. J. Propul. Power. 2015, 31, 1003-1013. [CrossRef]

9. Li, L.; Fan, X.J.; Wang, J. Measurements of wall heat flux and temperature in a supersonic model combustor. In Proceedings of the 47th AIAA/ASME/SAE/ASEE Joint Propulsion Conference and Exhibit, San Diego, CA, USA, 31 July-3 August 2011.

10. Cheng, D.; Wang, J.; Lu, Y.; Li, L.; Yao, W.; Fan, X.J. Wall heat flux measurements for a kerosene-fueled supersonic combustor. J. Aerosp. Eng. 2019, 32, 04019080. [CrossRef]

11. Cui, M.; Mei, J.; Zhang, B.-W.; Xu, B.-B.; Zhou, L.; Zhang, Y. Inverse identification of boundary conditions in a scramjet combustor with a regenerative cooling system. Appl. Therm. Eng. 2018, 134, 555-563. [CrossRef]

12. Wang, X.; Zhong, F.Q.; Gu, H.B.; Zhang, X.Y. Numerical study of combustion and convective heat transfer of a Mach 2.5 supersonic combustor. Appl. Therm. Eng. 2015, 89, 883-896. [CrossRef]

13. Cheng, L.W.; Zhong, F.Q.; Gu, H.B.; Zhang, X.Y. Application of conjugate gradient method for estimation of the wall heat flux of a supersonic combustor. Int. J. Heat Mass Transf. 2016, 96, 249-255. [CrossRef]

14. Sobel, D.R.; Spadaccini, L.J. Hydrocarbon fuel cooling technologies for advanced propulsion. J. Eng. Gas Turb. Power 1997, 119, 344-351. [CrossRef]

15. Zhao, Y.; Wang, Y.; Liang, C.; Zhang, Q.Y.; Li, X.Y. Heat transfer analysis of n-decane with variable heat flux distributions in a mini-channel. Appl. Therm. Eng. 2018, 144, 695-701. [CrossRef]

16. Lv, L.L.; Wen, J.; Fu, Y.C.; Quan, Y.K.; Zhu, J.Q.; Xu, G.Q. Numerical investigation on convective heat transfer of supercritical aviation kerosene in a horizontal tube under hyper gravity conditions. Aerosp. Sci. Technol. 2020, 105, 105962. [CrossRef]

17. Wang, Y.H.; Lu, Y.N.; Li, S.F.; Dong, M. Numerical study on non-uniform heat transfer deterioration of supercritical RP-3 aviation kerosene in a horizontal tube. Chin. J. Chem. Eng. 2020, 28, 1542-1557. [CrossRef]

18. Sun, X.; Meng, H.; Zheng, Y. Asymmetric heating and buoyancy effects on heat transfer of hydrocarbon fuel in a horizontal square channel at supercritical pressures. Aerosp. Sci. Technol. 2019, 93, 105358. [CrossRef]

19. Sun, X.; Meng, H. Large eddy simulations and analyses of hydrocarbon fuel heat transfer in vertical upward flows at supercritical pressures. Int. J. Heat Mass Transf. 2021, 170, 120988. [CrossRef]

20. Lei, Z.L.; He, K.; Huang, Q.; Bao, Z.W.; Li, X.Y. Numerical study on supercritical heat transfer of n-decane during pyrolysis in rectangular tubes. Appl. Therm. Eng. 2020, 170, 115002. [CrossRef]

21. Lei, Z.L.; Liu, B.; Huang, Q.; He, K.; Bao, Z.W.; Zhu, Q.; Li, X.Y. Thermal cracking characteristics of n-decane in the rectangular and circular tubes. Chinese J. Chem. Eng. 2019, 27, 2876-2883. [CrossRef]

22. Li, Z.Z.; Wang, H.Y.; Jing, K.; Wang, L.M.; Li, Y.; Zhang, X.W.; Liu, G.Z. Kinetics and modeling of supercritical pyrolysis of endothermic hydrocarbon fuels in regenerative cooling channels. Chem. Eng. Sci. 2019, 207, 202-214. [CrossRef]

23. Li, Z.Z.; Liu, G.Z.; Zhang, R.L. Heat transfer to supercritical hydrocarbon fuel in horizontal tube: Effects of near-wall pyrolysis at high heat flux. Chem. Eng. Sci. 2021, 229, 115994. [CrossRef]

24. Xu, K.K.; Sun, X.; Meng, H. Conjugate heat transfer, endothermic fuel pyrolysis and surface coking of aviation kerosene in ribbed tube at supercritical pressure. Int. J. Therm. Sci. 2018, 132, 209-218. [CrossRef]

25. Zhao, W.Z.; Song, Z.C.; Li, H.Z.; Gu, H.F.; Tuo, X.B.; Zheng, Y.L.; Wang, H.J. Research on heat transfer characteristics of kerosene at supercritical pressure in circular tubes. Exp. Therm. Fluid Sci. 2018, 96, 507-515. [CrossRef]

26. Wang, Y.H.; Li, S.F.; Dong, M. Experimental investigation on heat transfer deterioration and thermoacoustic instability of supercritical-pressure aviation kerosene within a vertical upward circular tube. Appl. Therm. Eng. 2019, 157, 113707. [CrossRef]

27. Sun, X.; Xu, K.K.; Meng, H.; Zheng, Y. Buoyancy effects on supercritical-pressure conjugate heat transfer of aviation kerosene in horizontal tubes. J. Supercrit. Fluids 2018, 139, 105-113. [CrossRef]

28. Jiao, S.; Li, S.F.; Pu, H.; Dong, M.; Shang, Y. Investigation of pyrolysis effect on convective heat transfer characteristics of supercritical aviation kerosene. Acta Astronaut. 2020, 171, 55-68. [CrossRef]

29. Tao, Z.; Cheng, Z.Y.; Zhu, J.Q.; Li, H.W. Effect of turbulence models on predicting convective heat transfer to hydrocarbon fuel at supercritical pressure. Chin. J. Aeronaut. 2016, 29, 1247-1261. [CrossRef] 
30. Menter, F.R. Two-equation eddy-viscosity turbulence models for engineering applications. AIAA J. 1994, 32, 1598-1605. [CrossRef]

31. Goyne, C.P.; Hall, C.D.; O’Brien, W.F.; Schetz, J.A. The Hy-V scramjet flight experiment. In Proceedings of the 14th AIAA/AHI Space Planes and Hypersonic Systems and Technologies Conference, Canberra, ACT, Australia, 6-9 November 2006.

32. Ai, Q.; Xia, X.L.; Sun, F.X. Influences of wall thermal characteristics on thermal environment in supercritical combustors. J. Eng. Thermophys. 2009, 30, 1373-1375. (In Chinese)

33. Deng, H.W.; Zhu, K.; Xu, G.Q.; Tao, Z.; Zhang, C.B.; Liu, G.Z. Isobaric specific heat capacity measurement for kerosene rp-3 in the near-critical and supercritical regions. J. Chem. Eng. Data 2012, 57, 263-268. [CrossRef]

34. Deng, H.W.; Zhang, C.B.; Xu, G.Q.; Zhang, B.; Tao, Z.; Zhu, K. Viscosity measurements of endothermic hydrocarbon fuel from (298 to 788) K under supercritical pressure conditions. J. Chem. Eng. Data 2012, 57, 358-365. [CrossRef]

35. Deng, H.W.; Zhang, C.B.; Xu, G.Q.; Tao, Z.; Zhang, B.; Liu, G.Z. Density measurements of endothermic hydrocarbon fuel at suband supercritical conditions. J. Chem. Eng. Data 2012, 56, 2980-2986. [CrossRef]

36. Zhong, F.Q.; Fan, X.J.; Yu, G.; Li, J.G. Heat transfer of aviation kerosene at supercritical conditions. J. Thermophys. Heat Tr. 2009, 23, 543-550. [CrossRef]

37. Huber, M.L. NIST Thermophysical Properties of Hydrocarbon Mixtures Database (SUPERTRAPP); Version 3.2, User' Guide NIST Standard Reference Database; NIST: Gaithersburg, MD, USA, 2007.

38. Eckert, E.R.G. Survey of Boundary Layer Heat Transfer at High Velocities and High Temperatures; WADC Technical Report, No. 59-624; Wright Air Development Center: Dayton, OH, USA, 1960.

39. Sieder, E.N.; Tate, C.E. Heat Transfer and Pressure drop of Liquids in Tubes. Ind. Eng. Chem. 1936, 28, 1429-1435. [CrossRef] 